\title{
A Formação Salinas, Orógeno Araçuaí (MG): história deformacional e significado tectônico
}

\author{
Reginato Fernandes dos Santos ${ }^{1}$, Fernando Flecha Alkmim ${ }^{1}$ \& \\ Antônio Carlos Pedrosa-Soares ${ }^{2}$
}

\begin{abstract}
Resumo A Formação Salinas, constituída de meta-arenitos, metapelitos e metaconglomerados, tem como principal área de ocorrência as vizinhanças da cidade homônima (norte de MG), onde jaz em discordância sobre rochas do Grupo Macaúbas, a oeste, e é intrudida por corpos graníticos neoproterózicos e cambrianos, a leste. Quatro gerações de estruturas deformacionais foram caracterizadas nessa região e três delas afetam as rochas da Formação Salinas. Os elementos da fase mais antiga, $\mathrm{D}_{\mathrm{D}}$, correspondem a dobras, falhas e estruturas de convolução e são de natureza adiastrófica, sin-deposicional. Relacionadas ao desenvolvimento do Orógeno Araçuaí, têm-se as fases $\mathrm{D}_{1}, \mathrm{D}_{2}$ e $\mathrm{D}_{\mathrm{G}}$. A fase $\mathrm{D}_{1}$, representada por dobras e zonas de cisalhamento associadas a uma série de estruturas de pequena escala, teve lugar durante o Evento Brasiliano (585 a $560 \mathrm{Ma}$ ) e foi acompanhada de metamorfismo regional nas condições da fácies xisto verde a anfibolito. $\mathrm{A}$ fase $\mathrm{D}_{2}$, associada ao colapso distensional do orógeno (520 a $500 \mathrm{Ma}$ ), é marcada por um trem de dobras vergentes para ESE associadas a uma clivagem de crenulação e por zonas de cisalhamento normais. Estas estruturas afetam somente unidades do Grupo Macaúbas. A fase $\mathrm{D}_{\mathrm{G}}$, associada ao processo de intrusão das rochas graníticas da região, foi responsável pelo arqueamento das camadas da Formação Salinas, acompanhado por um evento de metamorfismo de contato. A constituição, idade, história deformacional e o cenário tectônico da Formação Salinas no Orógeno Araçuaí indicam que sua deposição deu-se em uma bacia sin-orogênica (flysch), desenvolvida entre uma margem passiva e uma frente orogênica em desenvolvimento.
\end{abstract}

Palavras-chave: Formação Salinas, Orógeno Araçuaí, Grupo Macaúbas, Evento Brasiliano.

\begin{abstract}
The Salinas Formation, Araçuai Orogen (MG): deformation history and tectonic significance The Salinas Formation, made up of metasandstones, metapelites and metaconglomerates, occurs mainly in the surroundings of the town of Salinas, northern Minas Gerais. In this region, rocks of the Salinas Formation lie unconformably on top of the Macaúbas Group on the west, and are intruded by Neoproterozoic and Cambrian granites on the east. Four generations of deformational structures were documented in this region, three of them affecting the Salinas rocks. The structures of the oldest phase, $\mathrm{D}_{\mathrm{D}}$, representing an episode of syn-sedimentary deformation, include folds, faults and convolute bedding. The subsequent phases, $\mathrm{D}_{1}, \mathrm{D}_{2}$ and $\mathrm{D}_{\mathrm{G}}$ are related to the development of the Araçuaí orogen. The $\mathrm{D}_{1}$ phase, represented by folds, shear zones, and a whole series of small-scale elements, took place during the Brasiliano event (585 to $560 \mathrm{Ma}$ ) and was associated to regional metamorphism in the green schist to amphibolite facies conditions. The $\mathrm{D}_{2}$ phase, corresponding to the extensional collapse of the orogen $(520$ to $500 \mathrm{Ma})$, is recorded by fold trains that cascade down to ESE. These structures are associated to a crenulation cleavage and normal-sense shear zones, which affect only the metasediments of the Macaúbas Group. The $\mathrm{D}_{\mathrm{G}}$ phase, related to the emplacement of granite bodies, caused folding and contact metamorphism in the Salinas rocks. The nature, age, deformation history and tectonic setting of Salinas Formation in the Araçuaí orogen point out to a deposition in a syn-collisional basin - a flysch basin -, developed between a passive margin and an orogenic front.
\end{abstract}

Keywords: Salinas Formation, Araçuaí Orogen, Macaúbas Group, Brasiliano event.

INTRODUÇÃO O Orógeno Araçuaí, como um dos sistemas orogênicos neoproterozóicos do Brasil (Pedrosa-Soares et al. 2001), ocupa a área compreendida entre o Cráton do São Francisco e margem continental leste brasileira (Fig. 1). Dentre as unidades litoestratigráficas que dele tomam parte, figura a Formação Salinas, exposta nas vizinhanças da cidade homônima, na região norte de Minas Gerais.
A Formação Salinas possui uma história de definição que tem o estudo estratigráfico e geocronológico de Lima et al. (2002) como estágio mais recente. Após este estudo, passou a ser entendida como uma unidade independente e não mais pertencente ao Grupo Macaúbas ao qual era correlacionada. Constituída por turbiditos depositados entre $588+/-24 \mathrm{Ma}$ e $500 \mathrm{Ma}$ (Pedrosa-Soares et al. 2008), e representando a unida- 


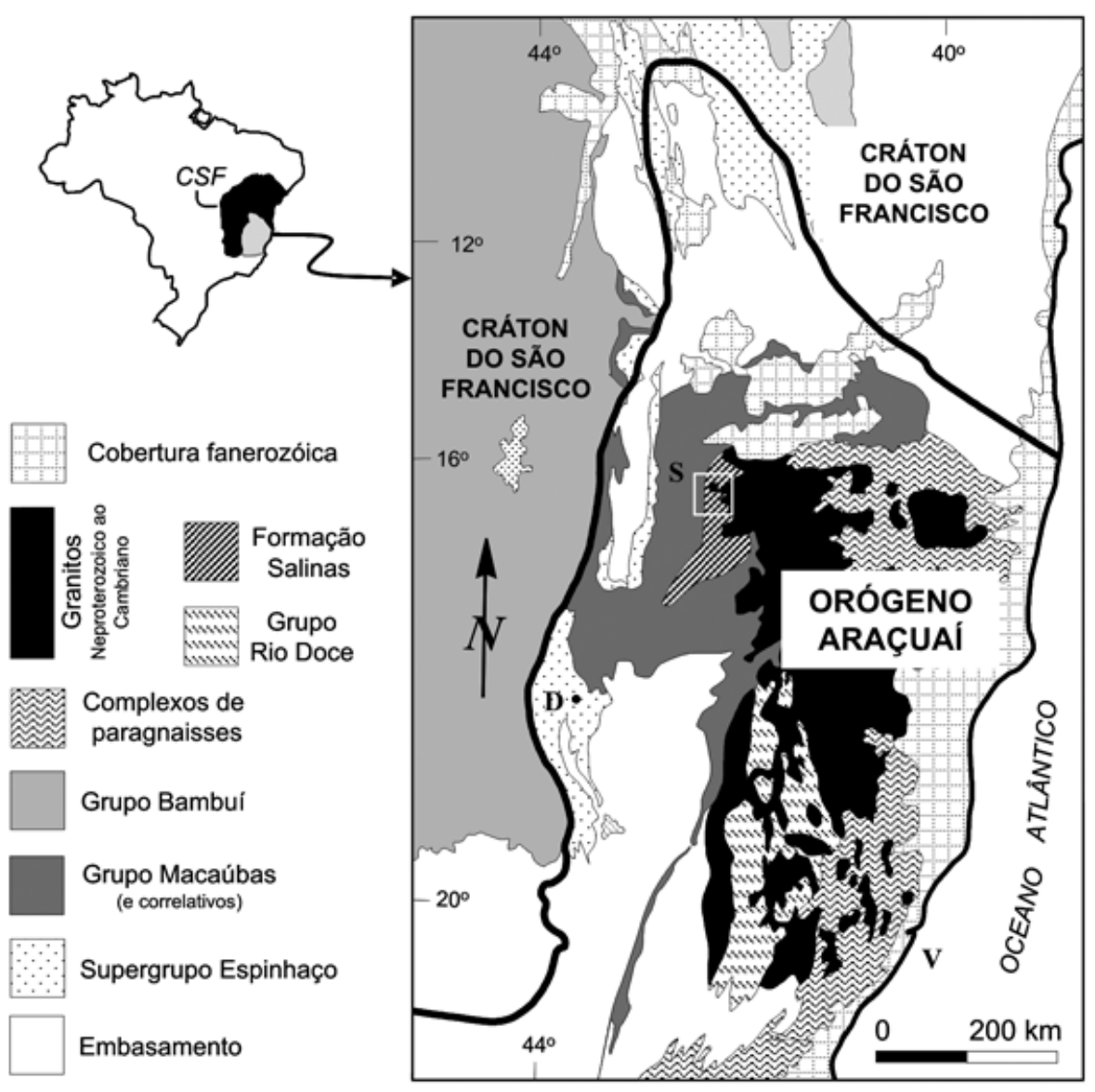

Figura 1 - Mapa geológico simplificado do Orógeno Araçuaí, com representação das grandes unidades estratigráficas e as principais estruturas. Cidades: $S=$ Salinas; $D=$ Diamantina $;=$ Vitória. A caixa indica a localização da área investigada. (Confeccionado a partir de Pedrosa-Soares et al. 2001).

de supracrustal mais jovem até agora caracterizada no Orógeno Araçuaí, a Formação Salinas possui outra particularidade: a sua ocorrência junto ao núcleo graníticoanatético na zona central do orógeno (Fig. 1), uma localização a princípio improvável, quando se levam em consideração a sua idade e a longa história de erosão experimentada pelo Orógeno Araçuaí.

Admitindo-se as interpretações de Lima et al. (2002) e levando-se em consideração as demais características da Formação Salinas, as seguintes questões surgem automaticamente: i) qual a natureza da Bacia Salinas? ii) sabendo-se que a deformação principal sinmetamórfica do Orógeno Araçuaí ocorrera por volta de $580 \mathrm{Ma}$ (Pedrosa-Soares et al. 2001), que estruturas deformacionais e processo(s) metamórfico(s) afetaram as rochas Salinas?

Objetivando responder as questões acima apresentadas, o presente trabalho reúne os resultados de uma investigação estrutural de detalhe levada a efeito nos litotipos da Formação Salinas, na região vizinha à cidade homônima, onde estão situadas as suas melhores exposições. A área escolhida para o estudo (Fig. 2) perfaz um total de aproximadamente $6000 \mathrm{~km}^{2}$ e se estende pelos municípios de Salinas, Taiobeiras, Rubelita e Coronel Murta em Minas Gerais e cobre, com estas dimensões, a principal ocorrência da Formação Salinas e unidades que com ela fazem contato.

\section{A FORMAÇÃO SALINAS NO CENÁRIO DA PORÇÃO NOROESTE DO ORÓGENO ARAÇU-} AÍ O Orógeno Araçuaí corresponde à parte brasileira da grande feição neoproterozóica do Gondwana Ocidental (Trompette 1994) denominada Orógeno Araçuaí-Congo Ocidental (Pedrosa Soares et al. 2001, Tack et al. 2001). Esta zona orogênica foi dividida durante a abertura do Oceano Atlântico, ficando como contraparte africana a Faixa Oeste-Congolesa (Trompette 1994, Pedrosa Soares et al. 2001). O Orógeno Araçuaí é limitado pelo Cráton do São Francisco, a norte e oeste, e pela margem continental atlântica, a leste (Fig. 1). O seu limite sul é feito com a Faixa Ribeira, em torno do paralelo $21^{\circ} \mathrm{S}$, onde seus traços estruturais rotacionamse de NNE-SSW para NE-SW (Pedrosa-Soares \& Wiedemann-Leonardos 2000).

A Formação Salinas tem sua ocorrência restrita à porção noroeste do Orógeno Araçuaí. Além dela, as demais unidades estratigráficas envolvidas nessa porção do orógeno são (Fig. 2): i) o embasamento mais velho que $1,8 \mathrm{Ga}$; ii) o Supergrupo Espinhaço e unidades correlativas de idades em torno de $1,75 \mathrm{Ga}$ e mais 

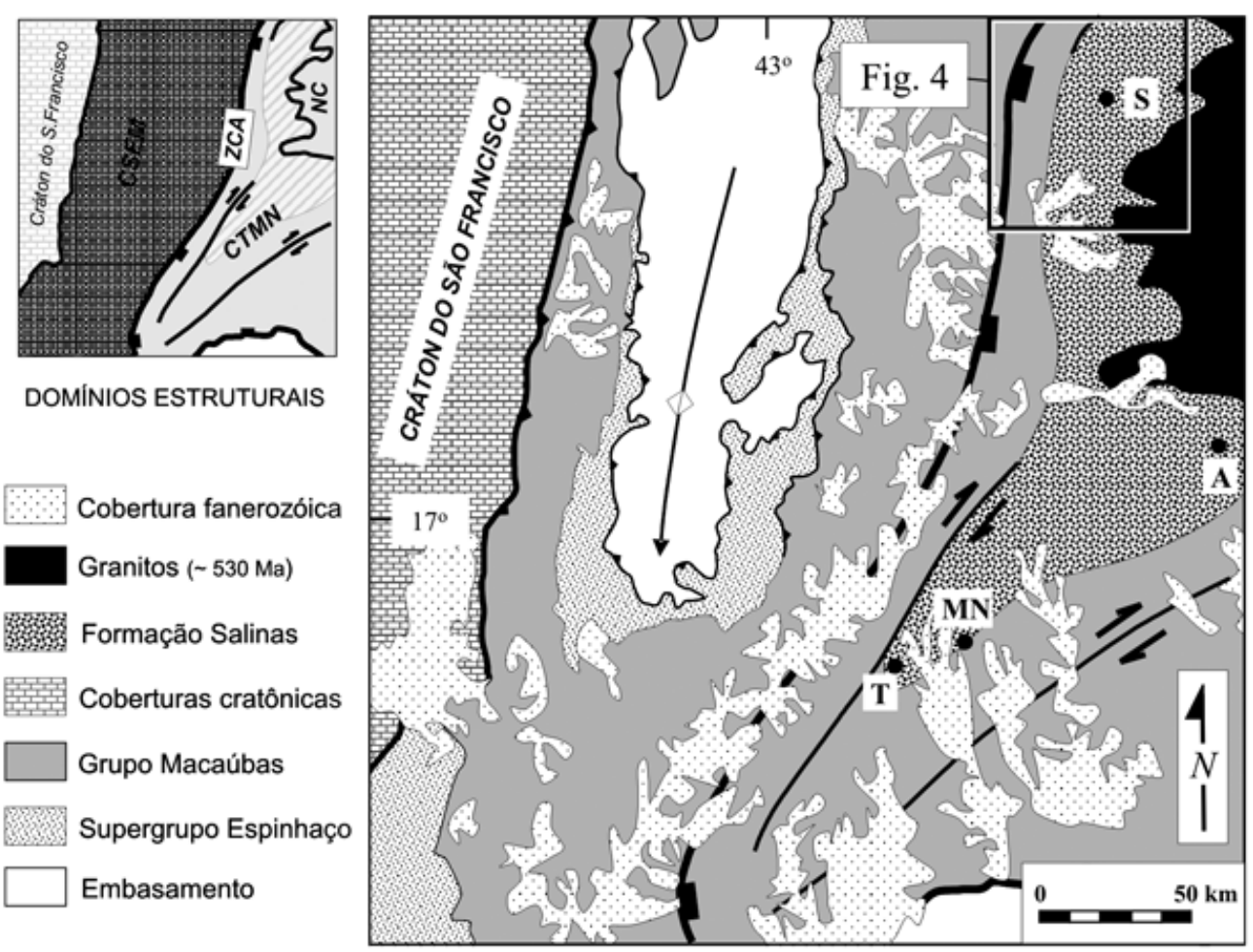

Figura 2 - Mapa geológico simplificado da porção noroeste do Orógeno Araçuaí, mostrando os domínios estruturais e as grandes unidades litoestratigráficas presentes na região. Domínios estruturais: CSEM = Cinturão de Empurrões e Dobramentos da Serra do Espinhaço; ZCA = Zona de Cisalhamento da Chapada Acauã; $C T M N=$ Corredor Transpressivo de Minas Novas; $N C=$ Núcelo Cristalino. Cidades: $S=$ Salinas; A = Araçuai; $M N=$ Minas Novas; $T$ = Turmalina . O quadro marcado com Fig.4 corresponde à área de estudo. (Modificado de Marshak et al. 2006).

jovens (Dussin \& Dussin 1995, Uhlein et al. 1998); iii) o Grupo Macaúbas e unidades correlativas que, em conjunto, caracterizam as fases rifte e de margem passiva da bacia precursora do orógeno, desenvolvida no Neoproterozóico, entre 920 e 740 Ma, sob influência glacial (Pedrosa-Soares et al. 1992, 2001; Uhlein et al. 1999); e $i v)$ rochas graníticas neoproterozóicas da Suíte G4 (530 Ma), que representam o magmatismo do estágio pós-colisional da evolução do orógeno (PedrosaSoares \& Wiedemann-Leonardos 2000).

Do ponto de vista tectônico, a porção noroeste do Orógeno Araçuaí abarca os seguintes domínios, discriminados por Alkmim et al. (2006) (Fig. 2):

- o Cinturão de Empurrões e Dobramentos da Serra do Espinhaço Meridional, junto ao limite leste do Cráton do São Francisco, que é caracterizado por um sistema de falhas reversas, de empurrão e dobras de orientação geral NS e vergentes para W (Almeida 1977, Uhlein 1991, Dussin \& Dussin 1995);

- a Zona de Cisalhamento da Chapada Acauã (Marshak et al. 2006) de natureza distensional e caracterizada por um trem de dobras vergentes para leste;

- o Corredor Transpressivo de Minas Novas (Pedrosa-Soares 1995) que compreende uma grande zona de cisalhamento dextral de direção NE-SW e envolve as rochas do Grupo Macaúbas e da Formação Salinas;
- o Núcleo Cristalino, marcado pelas suítes graníticas neoproterozóicas.

A história de definição da Formação Salinas remonta a Cobra (inédito). Segundo este autor, existiriam, na região de Salinas, $\mathrm{MG}$, dois pacotes distintos de rochas xistosas separados por uma falha denominada Falha de Taiobeiras: um a oeste, desprovido de pegmatitos, que representaria o Grupo "Macaúbas típico" e outro a leste, intrudido por pegmatitos e mais velho que o primeiro, por ele denominado "Grupo" Salinas. Já para Padilha (inédito), o "Grupo" Salinas representaria uma porção de mais alto grau metamórfico ("outro nível estrutural, mais profundo") do próprio Grupo Macaúbas, alçada por falha inversa.

Schobbenhaus et al. (1981) criam a "Unidade Proterozóica Gerada ou Retrabalhada no Ciclo Brasiliano", distinta do Grupo Macaúbas e que englobaria a seqüência de xistos aflorantes na região de Araçuaí e Salinas. Pedrosa-Soares (1984) incorpora parte da "Unidade Proterozóica Gerada ou Retrabalhada no Ciclo Brasiliano" ao Grupo Macaúbas e classifica como "Grupo Salinas" a seqüência de xistos que ocorreria a leste da Falha de Taiobeiras. Argumenta que os dados até então disponíveis não permitiriam uma correlação segura entre os grupos Macaúbas e Salinas, tal como por ele definidos. Karfunkel et al. (1985) reclassifica o 
Grupo Salinas em Unidade Salinas, ao sintetizar a estratigrafia do norte de Minas Gerais.

Pedrosa-Soares et al. (1990) fazem uma caracterização preliminar de uma seqüência vulcano-sedimentar na Faixa Araçuaí, denominada de Sequência Vulcano-sedimentar Ribeirão da Folha. Pedrosa-Soares et al. (1992) elevam a "Unidade" Salinas à categoria litoestratigráfica de formação, caracterizando-a como uma porção distal do Grupo Macaúbas. Para Pedrosa-Soares (1995), a Formação Salinas seria constituída, predominantemente, por uma sucessão de quartzo-mica-xistos, onde a estrutura bandada refletiria o acamamento, evidenciado por variações composicionais e granulométricas rítmicas. Enfatiza ainda que, nas zonas de baixa intensidade de deformação, tais rochas poderiam mostrar estruturas sedimentares, dentre elas gradação granulométrica, laminação cruzada e marcas de sola. Noce et al. (1997) também descrevem a Formação Salinas como uma das oito unidades do Grupo Macaúbas, constituída por quartzo-mica-xistos bandados, metagrauvacas, rochas cálciosilicáticas, metaconglomerados e grafita-xistos.

Pedrosa-Soares \& Wiedemann-Leonardos (2000) e Pedrosa-Soares et al. (2001) subdividem a Formação Salinas em duas unidades: proximal e distal. A unidade proximal teria um caráter estritamente sedimentar, enquanto a distal representaria uma unidade vulcano-sedimentar, com remanescentes de crosta oceânica neoproterozóica. Essa última unidade recebeu a denominação de Ribeirão da Folha-Dom Silvério, em função de sua distribuição geográfica.

Lima et al. (2002) descrevem na sucessão da Formação Salinas (no sentido de Pedrosa-Soares \& Wiedemann-Leonardos 2000) grauvacas, arenitos grauvaquianos, pelitos grauvaquianos e conglomerados clasto-suportados metamorfisados na fácies xisto-verde. Nela caracterizam nove fácies sedimentares e postulam, como ambiente deposicional, uma plataforma relativamente estreita, associada a talude e bacia profunda, onde a deposição dos sedimentos se daria por fluxos gravitacionais e correntes de turbidez. Levando em consideração a existência de discordância angular com as rochas sobrejacentes, o metamorfismo contrastante com o zoneamento esperado para sua zona de ocorrência, e novos dados geocronológicos, propõem a retirada da Formação Salinas do Grupo Macaúbas. Segundo a concepção destes autores, a Formação Salinas redefinida cobriria uma área de aproximadamente $3.800 \mathrm{~km}^{2}$, situada na porção noroeste do Orógeno Araçuaí, como é, mostrado no mapa da figura 2.

Do ponto de vista estrutural, as rochas da Formação Salinas, ainda que não individualizadas como hoje, foram objeto de algumas considerações em estudos de caráter regional (por exemplo, Karfunkel et al 1981, Pedrosa-Soares 1984, 1995, Ulhein et al. 1986, Costa 1989, Pedrosa-Soares \& Saadi 1989, Uhlein et al. 1990, Uhlein 1991, Crocco-Rodrigues et al. 1993, Grossi Sad et al. 1997 e Marshak et al. 2006).

De acordo com vários autores, o contato entre as rochas do Grupo Macaúbas e da Formação Salinas seria marcado pela chamada Falha de Taiobeiras (Jardim et. al. 1980), anteriormente conhecida como Falha de Salinas (Fontes et al. 1978) e também registrada, em mapa, por Schobbenhaus et al. (1978). Pedrosa-Soares \& Saadi (1989) representam a Falha de Taiobeiras como um lineamento regional de direção N30E, que mostra, a sul, uma inflexão para N10E. De acordo com Pedrosa-Soares \& Saadi (1989), essa inflexão concorda com as variações dos traços estruturais regionais, que por sua vez, seriam a expressão da xistosidade principal da Formação Salinas. Esses autores descrevem ainda, que a curvatura no lineamento referente à Falha de Taiobeiras, a partir de Salinas, é concordante com o arco descrito pela Faixa Araçuaí naquela região. Uhlein (1991), ao procurar pela ocorrência dessa estrutura no vale do Rio Araçuaí e na BR 251 nas proximidades da cidade de Turmalina, não a encontrando, concluiu que o contato entre o Grupo Macaúbas e Salinas poderia se dar de duas formas: ou por um feixe falhas inversas, ou de modo gradativo, sem estas estruturas.

Fontes et. al. (1978), Correia-Neves et. al. (1983), Pedrosa-Soares (1984), Saadi \& Pedrosa-Soares (1990) e Ulhein (1991) descrevem como estruturas de pequena escala presentes nas rochas Macaúbas, na região em apreço, uma xistosidade principal $\left(\mathrm{S}_{1}\right)$ com direção NE e mergulho para SE, com variações na direção de NNE até NS, além de dobras apertadas, isoclinais e complexas.

Uma clivagem de crenulação $\left(S_{2}\right)$ fora também caracterizada na região e interpretada por Correia Neves et al. (inédito) como associada a macrodobras assimétricas, cujos eixos se posicionariam entre NNW e NE. Essa mesma clivagem $\left(\mathrm{S}_{2}\right)$ foi, mais tarde, interpretada por Marshak et al. (2006) relacionada a dobras de segunda geração vergentes para leste, características da estrutura que estes autores denominaram Zona Distensional Chapada Acauã.

Uma terceira família de estruturas ocorre na região. Correia Neves et al. (inédito) e Pedrosa-Soares (1984) relacionaram-nas às intrusões graníticas, as quais deformariam as estruturas pré-existentes, verticalizando eixos de dobras e re-orientando os mergulhos da xistosidade principal.

Marshak et al. (2006) descrevem a Formação Salinas como uma unidade diferenciada das demais pertencentes ao Grupo Macaúbas. Essa diferenciação residiria no fato das rochas Salinas não conterem feições metamórficas e deformacionais compatíveis com aquelas presentes nas unidades subjacentes.

Os metassedimentos da Formação Salinas possuem um acervo geocronológico de dezesseis determinações Rb-Sr (Sá 1977), duas determinções K-Ar, em biotita, (Siga Jr. 1986) e quinze determinações U-Pb, em zircões detríticos (Lima et. al. 2002). Na região de Virgem da Lapa, Araçuaí e Coronel Murta, Sá (op. cit) obteve uma isócrona Rb-Sr de $660 \pm 60 \mathrm{Ma}$. Siga Jr. (1986), também na região de Araçuaí, encontrou uma idade de $630 \pm 30 \mathrm{Ma}$, pelo método Rb-Sr. Ambos os valores foram interpretados como idade de metamorfismo dessas rochas, em condições da fácies anfibolito. Uma idade de $477 \pm 16 \mathrm{Ma}$ foi obtida pelo método K-Ar, em biotitas, por Siga Jr (op. cit.) e interpretada 
como idade de resfriamento. Idades U-Pb SHRIMP obtidas em zircões detríticos, extraídos de meta-arenitos Salinas por Lima et al. (2002), formam três conjuntos distintos: 568 - $599 \mathrm{Ma}, 649$ - $680 \mathrm{Ma}$ e em torno de $1890 \mathrm{Ma}$. Estes resultados possibilitaram aos autores a determinação da idade máxima de 568 Ma para sedimentação da unidade. Como ela é intrudida por corpos graníticos cambrianos, o intervalo de tempo entre 568 e $500 \mathrm{Ma}$ foi o estimado para sua deposição (Lima et al. 2002). Os dados de Lima et al. (2002) foram re-analisados e re-interpretados por Pedrosa-Soares et al. (2008), que concluem por uma idade máxima de 588+/-24 Ma, e não de $568 \mathrm{Ma}$, para deposição da Formação Salinas. Estes autores também referem idades entre 600 a 630 Ma para zircões extraídos de seixos de rochas félsicas dos conglomerados Salinas. Com base nestes dados, Pedrosa-Soares et al. (2008) sugerem que o arco magmático do Orógeno Araçuaí seria a única fonte possível para seixos de rochas vulcânicas e zircões mais jovens da Formação Salinas.

PRINCIPAIS ELEMENTOS DA GEOLOGIA DA REGIÃO DE SALINAS

Estratigrafia As unidades litoestratigráficas pré-cam- brianas que ocorrem na área estudada são o Grupo Macaúbas, a Formação Salinas e corpos graníticos cambrianos da Suíte G4 (Pedrosa-Soares \& Wiedemann-Leonardos 2000). Todas elas acham-se parcialmente cobertas pelos sedimentos da Formação São Domingos, de idade cenozóica (Pedrosa-Soares 1984) (Figs. 3 e 4).

O GRUPO MACAÚBAS Metapelitos, meta-arenitos e metadiamictitos das Formações Chapada Acauã e Nova Aurora (Pedrosa-Soares \& Oliveira 1997) representam, na região, o Grupo Macaúbas e ocorrem quase que exclusivamente na porção oeste da área; há apenas uma exposição na sua porção centro sul, onde ocupam o núcleo de uma culminação antiformal (Fig. 4).

Os metapelitos compreendem filitos carbonosos e granatíferos, metassiltitos e, mais raramente, quartzo-mica xistos finos. Estas rochas apresentam-se, em geral, em pacotes contínuos com espessuras na casa das dezenas de metros. Os meta-arenitos correspondem a sericita-quartzitos e hematita-quartzitos que afloram como corpos lenticulares de espessura máxima estimada em cerca de 10 metros. Os metadiamictitos representam o litotipo mais abundante do Grupo Macaúbas e possuem clastos de quartzo, quartzito, carbonato, filito,

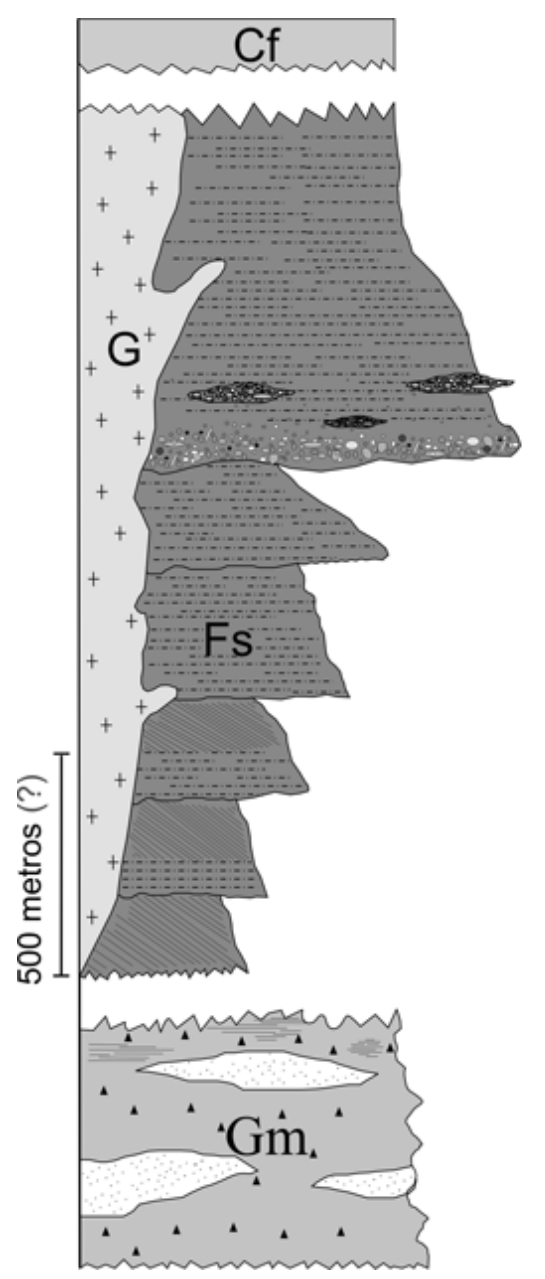

Legenda

Litologias

Coberturas Fanerozóicas: Formação São Domingos, depósitos elúvio-coluvionares

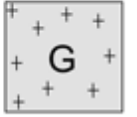

Granitos pegmatíticos e granitos a duas micas

Formação Salinas

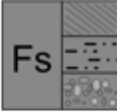

xistos

metarenitos

metaconglomerados

Grupo Macaúbas

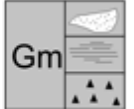

lentes de quartzitos, xistos, filitos

metadiamictitos

Figura 3 - Coluna estratigráfica esquemática para a região de Salinas (vide texto para explanação). 
gnaisse e granitóide.

A FORMAÇÃO SALINAS O conjunto de rochas aqui atribuído à Formação Salinas aflora na região investigada como uma faixa de direção geral NS, que mostra, a norte, uma leve inflexão para NE (Fig. 4). Esta faixa ocupa aproximadamente $40 \%$ da área estudada e possui uma largura bastante variável que fica, em média, na casa dos $25 \mathrm{~km}$. A Formação Salinas é constituída por metaconglomerados, meta-arenitos e metapelitos (quarzto-mica xistos) (Fig. 3).

Os metaconglomerados são o litotipo menos abundante da formação e afloram ao longo de uma faixa de direção geral NS, que se estende por cerca de 70 $\mathrm{km}$, na porção central da área estudada. Apresentam-se em camadas descontínuas, na forma de lentes, com espessuras entre 5 e 15 metros, podendo, entretanto, atingir até 50 metros. Seus contatos com os demais litotipos mostram-se irregulares e são, provavelmente, de caráter erosivo. A maioria dos corpos descritos é suportada pelos clastos de quartzo, quartzito, gnaisse, granitóide, meta-arenito e rochas vulcânicas, cujos diâmetros ficam compreendidos entre 5 e 10 centímetros, podendo, entretanto, alcançar a casa dos 50 centímetros. A matriz é, em geral, escassa e constituída por quartzo, biotita, muscovita, plagioclásio, calcita e clorita.

Os meta-arenitos perfazem cerca de $50 \%$ da espessura da porção exposta da Formação Salinas e formam sucessões rítmicas com metapelitos. Seus melhores afloramentos situam-se nos arredores da cidade de Salinas, especialmente nos cortes das rodovias BR 251 e BR 342. Apresentam-se em pacotes homogêneos de até $30 \mathrm{~m}$ de espessura e, quando frescos, exibem coloração cinza escura. Mesoscopicamente, caracterizam-se pela ausência da foliação regional e pela presença de inúmeras estruturas sedimentares. Além de laminação e acamamento plano-paralelos, as estruturas sedimentares mais freqüentemente observadas nos meta-arenitos são: gradações granulométricas, ripples (em planta), ripple drift, climbing ripples, estratificação cruzada, pseudo-nódulos e estruturas em chama.

O terceiro litotipo da Formação Salinas corresponde aos metapelitos, representados pelo pacote de quartzo-mica xistos que ocorrem principalmente próximo ao contato da unidade com as rochas do Grupo Macaúbas, a oeste, e com as suítes graníticas, a leste. Nesses locais, as espessuras das camadas alcançam dezenas de metros. $\mathrm{O}$ acamamento e a laminação planoparalelos, marcados por variações nas proporções de mica e quartzo/feldspato, são as suas feições sedimentares mais freqüentes.

A SUITTE GRANÍTICA G4 A porção leste da área estudada (Fig. 4) caracteriza-se pelo franco predomínio de corpos graníticos, os quais acham-se intrudidos nas rochas da Formação Salinas (Pedrosa-Soares \& Oliveira 1997). Para efeito de mapeamento, todas as rochas graníticas que lá ocorrem foram interpretadas como componentes do Batólito Itaporé (Pedrosa-Soares \& Oliveira 1997). A análise de afloramentos propicia, porém, a separação de dois grupos distintos de rochas intrusivas: pegmatitos de composição granítica e granitos (Correia Neves et al. 1982, Pedrosa-Soares 1984, Monteiro 1986). Os pegmatitos, mais freqüentes na porção sul da área estudada, formam corpos irregulares e com dimensões variando entre um e uma centena de metros, e representam as fácies de cúpula dos plútons do Batólito Itaporé (Pedrosa-Soares 1984, Monteiro 1986, PedrosaSoares et al. 1987). Os granitos, a biotita e moscovita, foram caracterizados como leucogranitos a duas micas por Monteiro (1986). Constituem grandes maciços com certa homogeneidade, principalmente nas suas porções centrais. Junto aos contatos com as encaixantes, exibem nítida foliação de fluxo ígneo.

Os corpos graníticos caracterizam, na região, o magmatismo pós-colisional do Orógeno Araçuaí, cujas idades ficam no intervalo entre 535 e $500 \mathrm{Ma}$ (PedrosaSoares \& Wiedemann-Leonardos 2000, Pedrosa-Soares et al. 2001).

Arcabouço estrutural Compõem o panorama tectônico da região estudada, três grandes compartimentos estruturais, aqui designados $\mathrm{W}$ (oeste), C (central) e $\mathrm{E}$ (leste) (Fig. 4), todos eles integrantes da zona externa e início da zona interna do Orógeno Araçuaí ou Faixa Araçuaí, no sentido de Almeida (1977).

O compartimento W é marcado pela ocorrência de rochas do Grupo Macaúbas que tomam parte do Cinturão de Empurrões e Dobramentos da Serra do Espinhaço Meridional e de uma pequena porção da Saliência do Rio Pardo, tal como caracterizados por Alkmim et al. (2006). Tem como estrutura mais expressiva um grande antiforme de traço axial NNE e caimento de cerca de $20^{\circ}$ para NNE (Fig.4 e 5). Esta estrutura prolonga-se ainda para oeste e sul da área estudada, onde exibe um segundo fechamento, também suave e com caimento para SSW, configurando assim uma culminação antiformal vergente para oeste (Pedrosa-Soares \& Oliveira 1997). O compartimento W é separado do seu vizinho a leste pela Zona de Cisalhamento da Chapada Acauã, caracterizada por um trem de dobras vergentes para leste e superimpostas às estruturas vergentes para oeste, características do Cinturão da Serra do Espinhaço Meridional (Marshak et al. 2006, Alkmim et al. 2006) (Figs. 4 e 5).

Marca o limite entre os compartimentos W e $\mathrm{C}$, no setor noroeste da área investigada, uma descontinuidade de alto ângulo, de direção N35E (Fig. 4), que nas imagens se expressa como um nítido lineamento. Nas suas adjacências, as foliações das rochas Macaúbas e Salinas formam um leque divergente, configurando, aparentemente, uma estrutura em flor, aqui interpretada como uma zona de falha transcorrente dextral a reversa-dextral (Figs. 4 e 5). Na medida em que se avança para sul, adquire, progressivamente, a orientação NS e mergulhos mais baixos. Perde, pouco a pouco, a expressão nas imagens e deixa de existir na altura da coordenada UTM 8230000 (Fig. 4). Esta descontinuidade corresponde, em parte, à estrutura que marcaria o contato entre os metassedimentos Macaúbas e Salinas e originalmente designada como Falha de Taiobeiras por Jardim et al. (1980). 


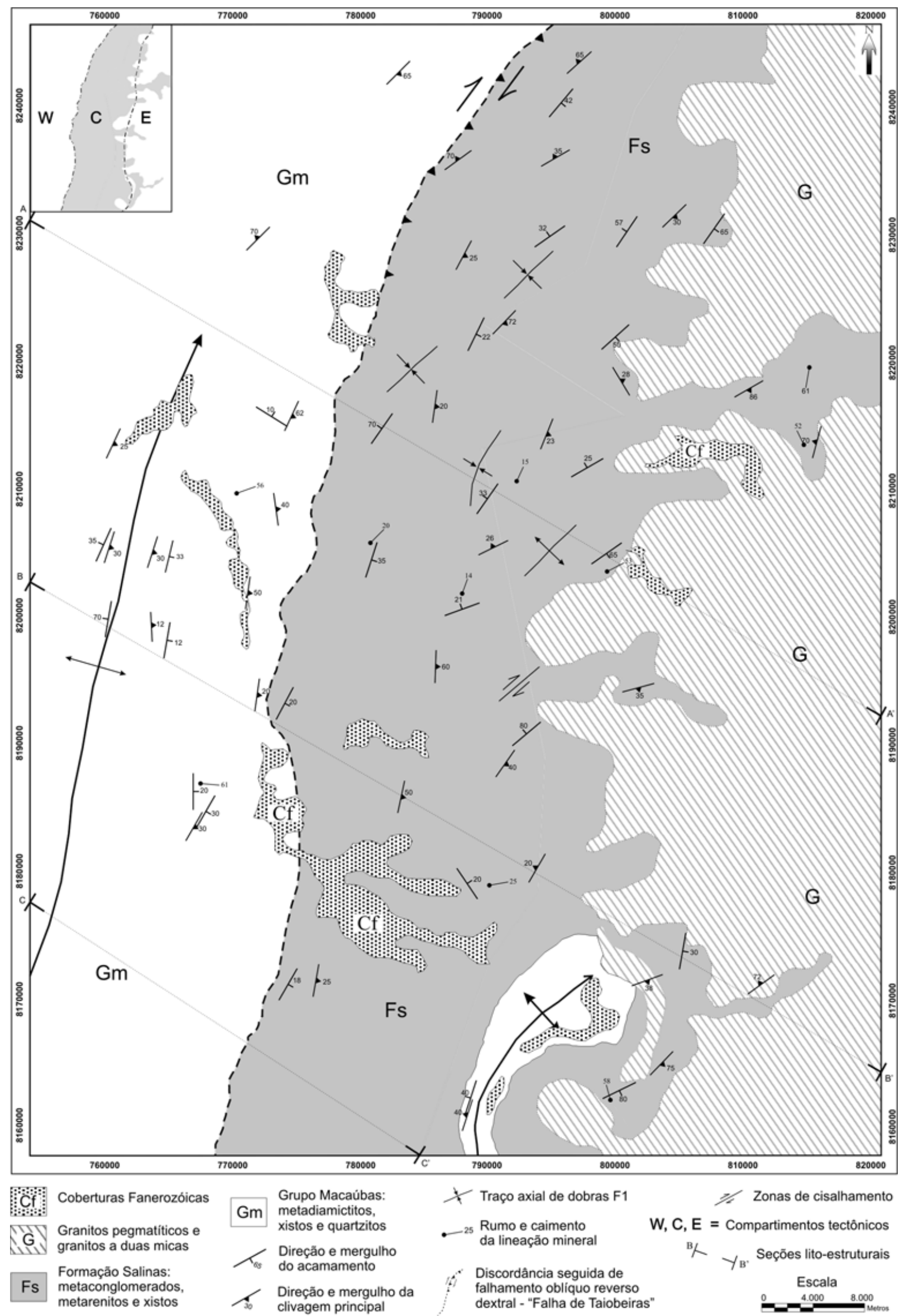

Figura 4 - Mapa geológico simplificado da área estudada, com a indicação dos domínios estruturais oeste $(W)$, central (C) e leste (E).(Confeccionado com base em Pedrosa-Soares \& Oliveira 1997). 

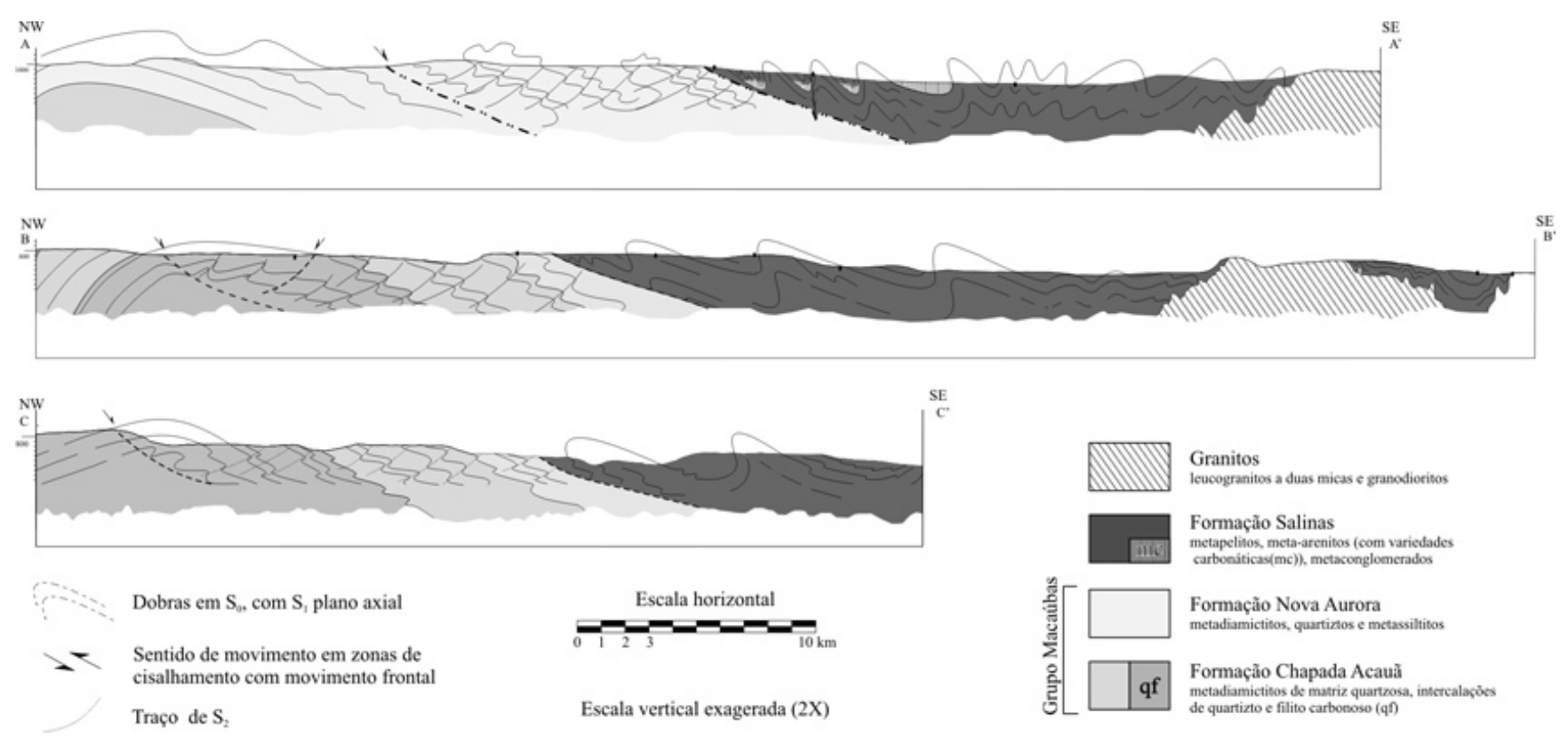

Figura 5 - Seções geológicas através da área investigada. A localização das mesmas é indicada no mapa da Fig.4. Notar na seção AA' a dupla vergência nas grandes dobras que afetam as rochas da Formação Salinas.

O compartimento $\mathrm{C}$, caracterizado pela ocorrência das rochas da Formação Salinas, apresenta-se em mapa como uma faixa de direção NNE-SSW de aproximadamente $25 \mathrm{~km}$ de largura média (Fig. 4). A geometria 3D do pacote Salinas neste compartimento configura uma cunha, no interior da qual a deformação é acomodada predominantemente por dobras de dupla vergência e, subordinadamente, por falhas de empurrão (Fig. 5). Tais dobras, presentes em todas as escalas, têm as charneiras posicionadas preferencialmente em torno de 007/34 e são muito freqüentes e de menor comprimento de onda na base da unidade, junto ao limite oeste do compartimento. Em direção a leste, tornam-se menos freqüentes e exibem comprimentos de onda da ordem de até $4 \mathrm{~km}$. Tem-se assim uma clássica geometria de cunha ou prisma tectônico, tal como documentada na natureza e em experimentos de modelagem física analógica (vide por exemplo, Elliot 1976, Chapple 1978, Davis et al. 1983) .

No compartimento E, granitos indeformados da Suíte G4 intrudem as rochas Salinas, que ali se encontram intensamente deformadas e metamorfisadas.

HISTÓRIA DEFORMACIONAL E METAMÓRFICA DA FORMAÇÃO SALINAS A investigação estrutural realizada nas rochas da Formação Salinas e demais unidades expostas nas vizinhanças da cidade homônima permitiu a caracterização de quatro gerações de estruturas deformacionais. A mais antiga delas é de natureza adiastrófica e as demais estão relacionadas ao desenvolvimento do Orógeno Araçuaí. São elas as seguintes:

- Fase de deformação $\mathrm{D}_{\mathrm{D}}$, sin-deposicional, durante a qual formaram-se dobras, falhas e estruturas de convolução. Registradas exclusivamente nas rochas da
Formação Salinas, estas estruturas refletem um ambiente no qual atuavam processos sedimentares de alta energia.

- Fase de deformação $\mathrm{D}_{1}$, no decorrer da qual nuclearam-se, sob um campo compressional E-W, dobras, falhas, zonas de cisalhamento dúcteis e estruturas menores de orientação preferencial NE-SW e dupla vergência, as quais dominam o panorama estrutural da região.

- Fase de deformação $\mathrm{D}_{2}$, durante a qual nucleou-se a zona de cisalhamento distensional da Chapada Acauã, marcada por um trem de dobras vergentes para SE, as quais se associam uma clivagem de crenulação e um conjunto de zonas de cisalhamento normais. Esta fase tem seus registros somente nas rochas do Grupo Macaúbas e foi interpretada por Marshak et al. (2006), como uma manifestação do colapso gravitacional do Orógeno Araçuaí.

- Fase de deformação $\mathrm{D}_{\mathrm{G}}$, durante a qual intrusões graníticas, localizadas essencialmente na porção leste da área, deformaram a cobertura adjacente, produzindo arqueamentos e dobras.

As fases de deformação $D_{D}, D_{1}$ e $D_{2}$ se sucedem nesta ordem de cronologia relativa, como demonstram as relações de corte e superposição entre seus elementos. Já as estruturas da fase $\mathrm{D}_{\mathrm{G}}$ podem ser pré, sin ou pós- $\mathrm{D}_{2}$; suas relações são indeterminadas, uma vez que relações de corte e superposição não foram observadas.

No pacote de rochas Salinas há uma grande variação na intensidade da deformação. Por amplas áreas, os metassedimentos, destituídos de estruturas deformacionais macroscópicas, compõem grandes feições homoclinais. Há uma tendência, entretanto, para que as rochas pelíticas, mais freqüentes na porção basal e oeste da zona de ocorrência da unidade, apresentem-se mais intensamente deformados que os meta-arenitos, mais freqüentes na porção superior da Formação Salinas e 
no setor centro-leste da área estudada. A relativa escassez de estruturas deformacionais nas rochas expostas nos arredores da cidade de Salinas já havia sido notada por outros autores, o que os levou a considerá-las praticamente isentas de metamorfismo e deformação (por exemplo, Lima et al. 2002, Marshak et al. 2006).

A fase $\mathrm{D}_{1}$ é acompanhada pelo evento de metamorfismo regional $\mathrm{M}_{1}$, o qual se processa nas condições das fácies xisto verde a anfibolito. Como manifestações deste evento, têm-se nas rochas Macaúbas a paragênese biotita + muscovita + quartzo + granada (almandina) + estaurolita e nas rochas Salinas, todas estes minerais, com exceção da estaurolita. Quando se analisa a distribuição, pela área estudada, das paragêneses associadas ao evento $\mathrm{M}_{1}$, observa-se um decréscimo nas condições metamórficas de oeste para leste, o que não é esperado face à polaridade do Orógeno Araçuaí e a vergência sistemática das estruturas dirigidas para oeste.

A fase $\mathrm{D}_{\mathrm{G}}$, por sua vez, é acompanhada por metamorfismo de contato (Pedrosa-Soares 1984), registrado nas rochas da Formação Salinas na porção leste da área estudada através da adição de estaurolita e sillimanita à paragênese anteriormente mencionada. Além disso, naquela região, as rochas exibem granulação mais grossa e recristalização estática de grãos e agregados de quartzo.

Estruturas da fase $D_{\mathrm{D}}$, sindeposicionais Em várias exposições, as rochas Salinas exibem estruturas de caráter sin-sedimentar, dentre as quais destacam-se: $i$ ) dobras de escala até decimétrica; ii) falhas normais isoladas ou em arranjos em dominó, de dimensões milimétricas a centiméticas; iii) brechas intraformacionais; iv) estruturas de escape de fluidos; e $v$ ) pseudonódulos (Fig. 6). Tais feições apresentam-se confinadas a estratos individuais e são afetadas por elementos da fase de deformação $D_{1}$.

A deformação em pacotes sedimentares em processo de crescimento ocorre, predominantemente, em função da mudança de pressão de fluidos nos poros, o que gera uma desestabilização no arcabouço dos grãos, dando origem à liquefação e à fluidização. Segundo Lowe (1975), essa desestabilização associa-se à passagem de ondas de tempestade e de correntes de densidade, ao impacto da quebra de ondas e a abalos sísmicos.

De um modo geral, as estruturas sin-deposicionais observadas atestam fluxo de material dirigido de norte para sul, com dispersões para SE e SW, o que indicaria um gradiente bacinal no mesmo sentido. De fato, a análise de paleocorrentes e distribuição das fácies da Formação Salinas apontam para uma alimentação sedimentar a partir do norte e acumulação em uma calha de orientação geral NE-SW. Porém, outras fontes contribuíram para a unidade, pois, a ocorrência de clastos e zircões oriundos do arco magmático do orógeno implica em alimentação também a partir de sul e sudeste.

\section{Estruturas da fase $D_{1}$}

DOBRAS $F_{l}$ As dobras $\mathrm{F}_{1}$ acham-se distribuídas por toda a área estudada e representam as estruturas tectônicas dominantes. São vergentes tanto para WNW como para ESE, variam entre suaves e isoclinais e pos- suem comprimentos de onda da ordem dos centímetros aos vários quilômetros (Figs. 4, 5 e 7). Marcam-nas a superfície do acamamento, em geral bem preservado e associado a uma grande variedade de estruturas sedimentares. Suas charneiras caem de 10 a $40^{\circ}$, preferencialmente, para NNE (Fig. 9). Exemplos de dobras $F_{1}$ de grande escala e duplo caimento podem ser observados nos compartimentos $\mathrm{W}$ (envolvendo rochas do Grupo Macaúbas) e E (envolvendo rochas do Grupo Macaúbas e Fm. Salinas) (Figs. 4 e 5).

O estereograma do acamamento para toda a área investigada mostra uma grande dispersão em torno do eixo $(\beta)=040 / 08$, que é bastante distinto dos eixos medidos da dobras $\mathrm{F}_{1}$ (orientação preferencial de 007/34) (compare Figs. 8 e 9). Isto se dá pelo fato das atitudes do acamamento refletirem não só as dobras $\mathrm{F}_{1}$, mas todas as estruturas deformacionais presentes na região.

O comprimento de onda e a vergência das dobras $F_{1}$ variam conforme a região considerada. Na porção oeste do compartimento $\mathrm{C}$, onde predominam rochas pelíticas, os comprimentos de onda são menores e as vergências sistematicamente dirigidas para WNW. Por outro lado, nas porções central e leste do compartimento C, onde predominam os meta-arenitos, as dobras $\mathrm{F}_{1}$ exibem comprimentos de onda de escala até quilométrica e vergem tanto para WNW, como para ESE (Fig. 5).

CLIVAGEM $S_{l}$ Disposta na posição plano-axial das dobras $\mathrm{F}_{1}$, a clivagem $\mathrm{S}_{1}$ se manifesta de várias maneiras, a depender da unidade e da região a ser considerada. Com uma orientação preferencial de 108/28, a clivagem $\mathrm{S}_{1}$ mostra, entretanto, uma considerável variação de atitude, como pode ser constatado no diagrama estereográfico da figura 8. Os pólos dos seus planos descrevem uma guirlanda em torno do eixo $(\beta)=048 / 15$, que inclui um segundo máximo de concentração de atitudes em torno $319 / 65$, bem menos representativo que o primeiro. A guirlanda como um todo reflete três fenômenos distintos: a dupla vergência das dobras $F_{1}$ e os dobramentos da clivagem $\mathrm{S}_{1}$ durante as fases $\mathrm{D}_{2}$ e $\mathrm{D}_{\mathrm{G}}$.

Nas rochas do Grupo Macaúbas e da Formação

Salinas, na metade oeste da área estudada, a clivagem $\mathrm{S}_{1}$, penetrativa em todas as escalas, se apresenta como uma xistosidade. Nestas condições, fica marcada pela orientação preferencial planar de minerais como biotita, quartzo, clorita, bem como pelo plano de achatamento dos clastos líticos dos metadiamictitos do Grupo Macaúbas (Fig. 10). Nos metadiamictitos Macaúbas, a xistosidade $\mathrm{S}_{1}$ exibe mergulhos relativamente mais altos e atitude modal de 108/28 (Fig. 8c). Nos pacotes da porção superior da Formação Salinas, mais ricos em meta-arenitos e expostos nos arredores da cidade homônima, a clivagem $\mathrm{S}_{1}$, quando presente, é reconhecível, macroscopicamente, nas intercalações pelíticas e nas camadas de metaconglomerados. Raramente, se manifesta nos pacotes de meta-arenitos; quando o faz corresponde a uma clivagem embrionária ou espaçada.

LINEAÇÕES DE ESTIRAMENTO $\left(L_{e s}\right)$ e INTERSEC$C$ CिO $\left(L_{i n}\right) \quad$ Nos xistos e meta-arenitos da Formação 

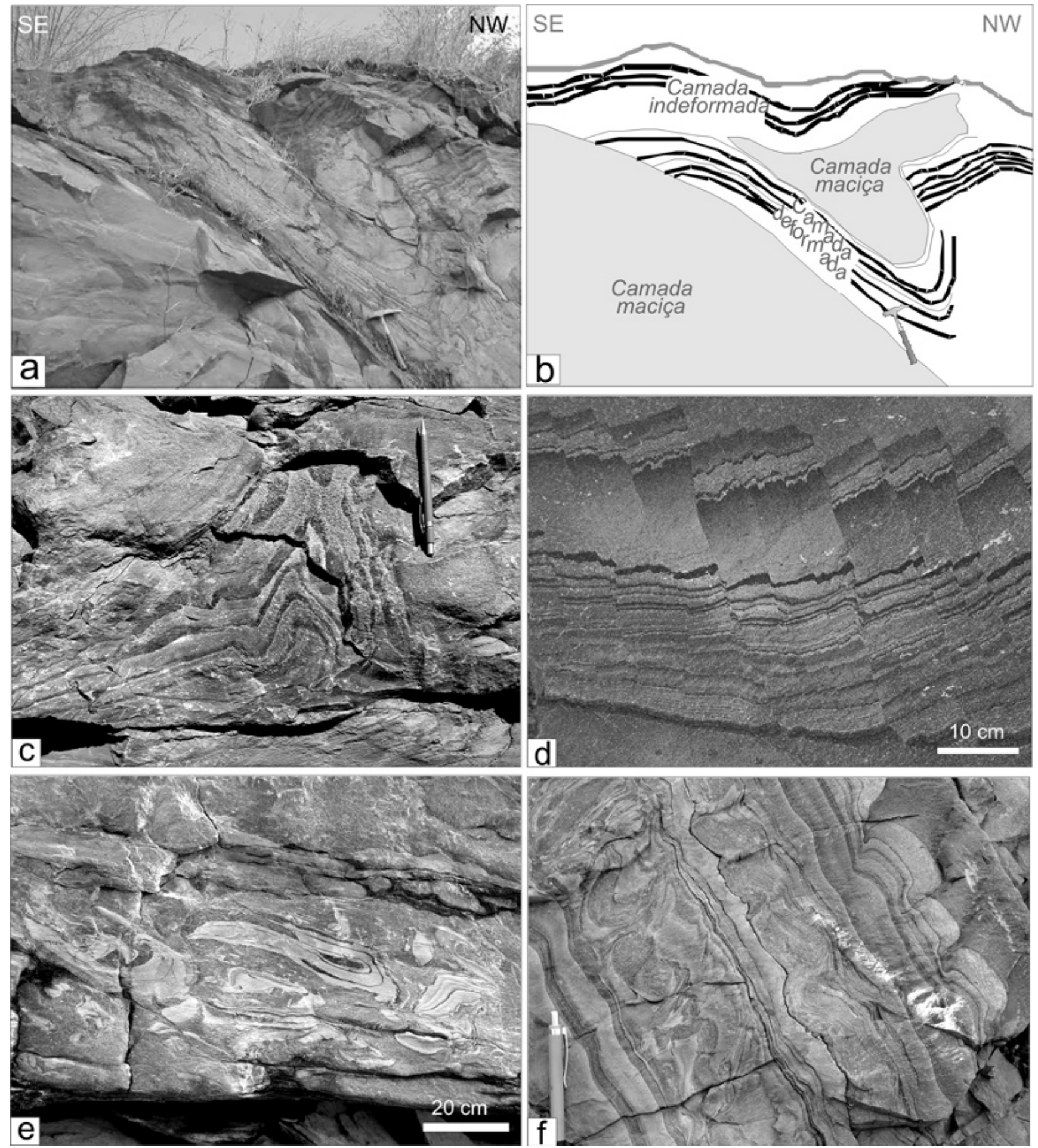

Figura 6 - Estruturas da fase $D_{D^{\circ}}$ a) Sinforme truncado no topo por camadas horizontais (BR $251-17 \mathrm{~km} \mathrm{a} \mathrm{NE}$ de Salinas). b) Representação esquemática da estrutura da foto anterior. c) Dobra convoluta em meta-arenitos expostas na BR 251 a $15 \mathrm{~km}$ para NE de Salinas. d) Conjunto de falhas normais em dominó, afetando metaritmitos (BR 251 - $17 \mathrm{~km}$ a NE de Salinas). e) Brecha intraformacional, cujos clastos correspondem a estratos de ritmitos dobrados e rompidos. f) Pseudonódulos (à direita) e dobras convolutas (à esquerda) em camadas invertidas da Fm. Salinas. ("e" e "f" estão expostas a 13 km de Salinas com acesso a NE da BR 251).

Salinas, a lineação de estiramento $\left(\mathrm{L}_{\text {est }}\right)$, contida na clivagem $\mathrm{S}_{1}$, é definida pela orientação preferencial linear de porfiroclastos e agregados de quartzo, cristais de biotita e, em alguns pontos, de cristais e agregados de fibrolita. Nos metadiamictitos do Grupo Macaúbas e metaconglomerados Salinas, marcam-na os clastos, em geral, achatados e estirados em diferentes intensidades. Nos litotipos da Formação Salinas, a lineação 

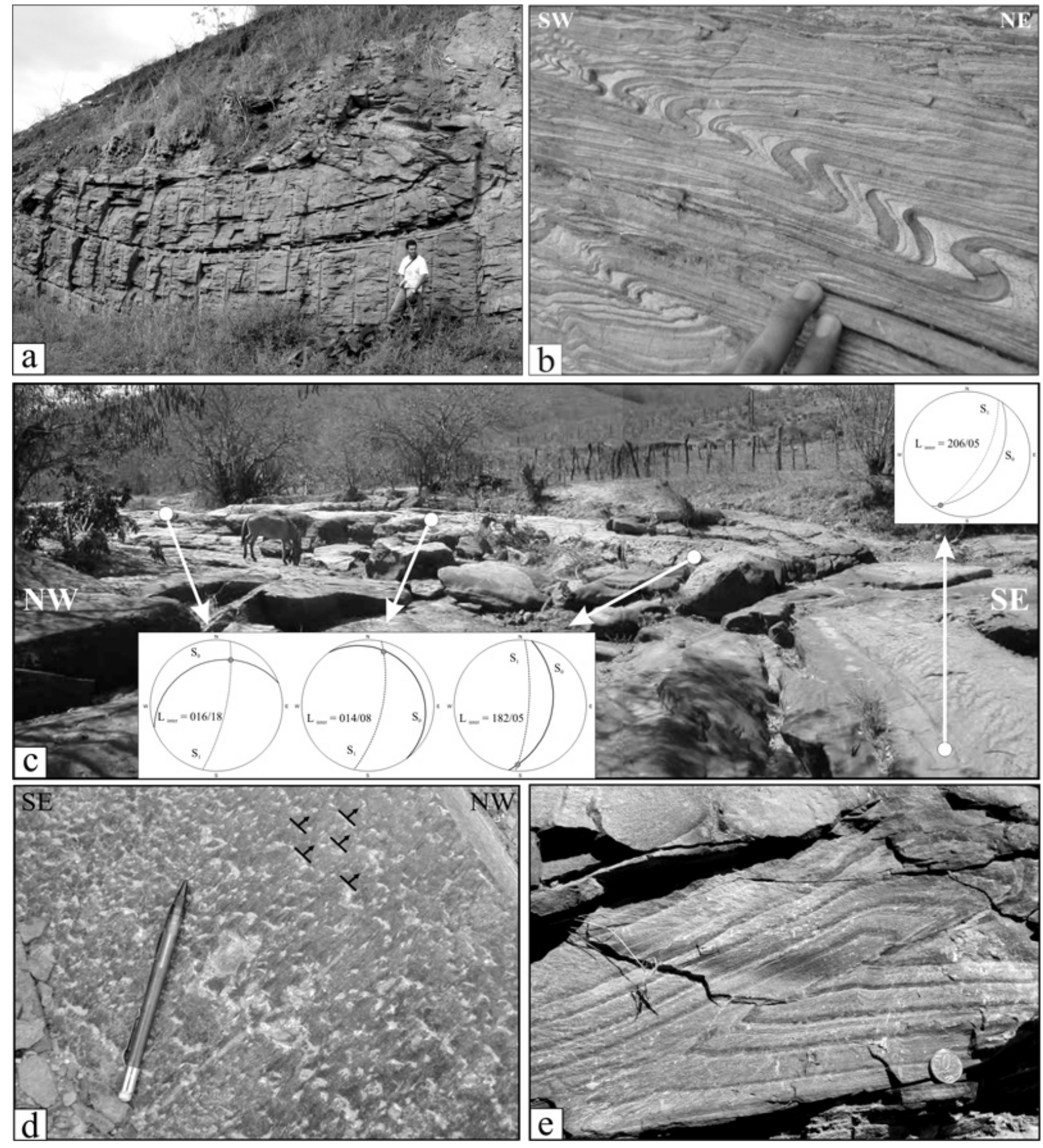

Figura 7 - Estruturas da fase $D_{1}$ na FM Salinas: a) Grande dobra $F_{1}$ fechada, deitada e vergente para SE, envolvendo meta-arenitos finos e metapelitos (arredores de Salinas). Os traços na posição do plano axial correspondem à clivagem $S_{l}$. b) Minidobras $F_{l}$ em ritmitos destituídos da clivagem $S_{1}$ (arredores de Salinas). c) Grande anticlinal aberto $F$ vergente para $N W$, envolvendo meta-arenitos e metapelitos (leito do Rio Canabrava a $20 \mathrm{~km}$ a sul de Salinas com acesso pela BR342). Os estereogramas mostram as relações entre $S_{0}$ e $S_{r}$ d) Vista em planta de uma zona de cisalhamento intra-estratal, na qual se observam turboglifos cisalhados e a lineação de estiramento $L_{\text {est }}$ Os "steps" indicam transporte tectônico no sentido NW (periferia de Salinas). e) Falha de empurrão de pequeno rejeito e dobra associada em ritmitos expostos em corte da BR 251, próximo a Salinas.

$\mathrm{L}_{\text {est }}$ possui a orientação preferencial de $086 / 24$, associada a uma considerável dispersão. Nas rochas do Grupo Macaúbas, sua orientação preferencial fica em 062/60 (Fig.9). Comparando-se estes valores com aqueles das orientações preferenciais da foliação $\mathrm{S}_{1}$, nota-se que $\mathrm{L}_{\text {est }}$ possui uma obliqüidade média variável entre $67^{\circ} \mathrm{e} 72^{\circ}$.

A lineação de intersecção $\left(\mathrm{L}_{\text {int }}\right)$, resultado da intersecção de $\mathrm{S}_{0}$ com $\mathrm{S}_{1}$, é mais expressiva nos meta- 

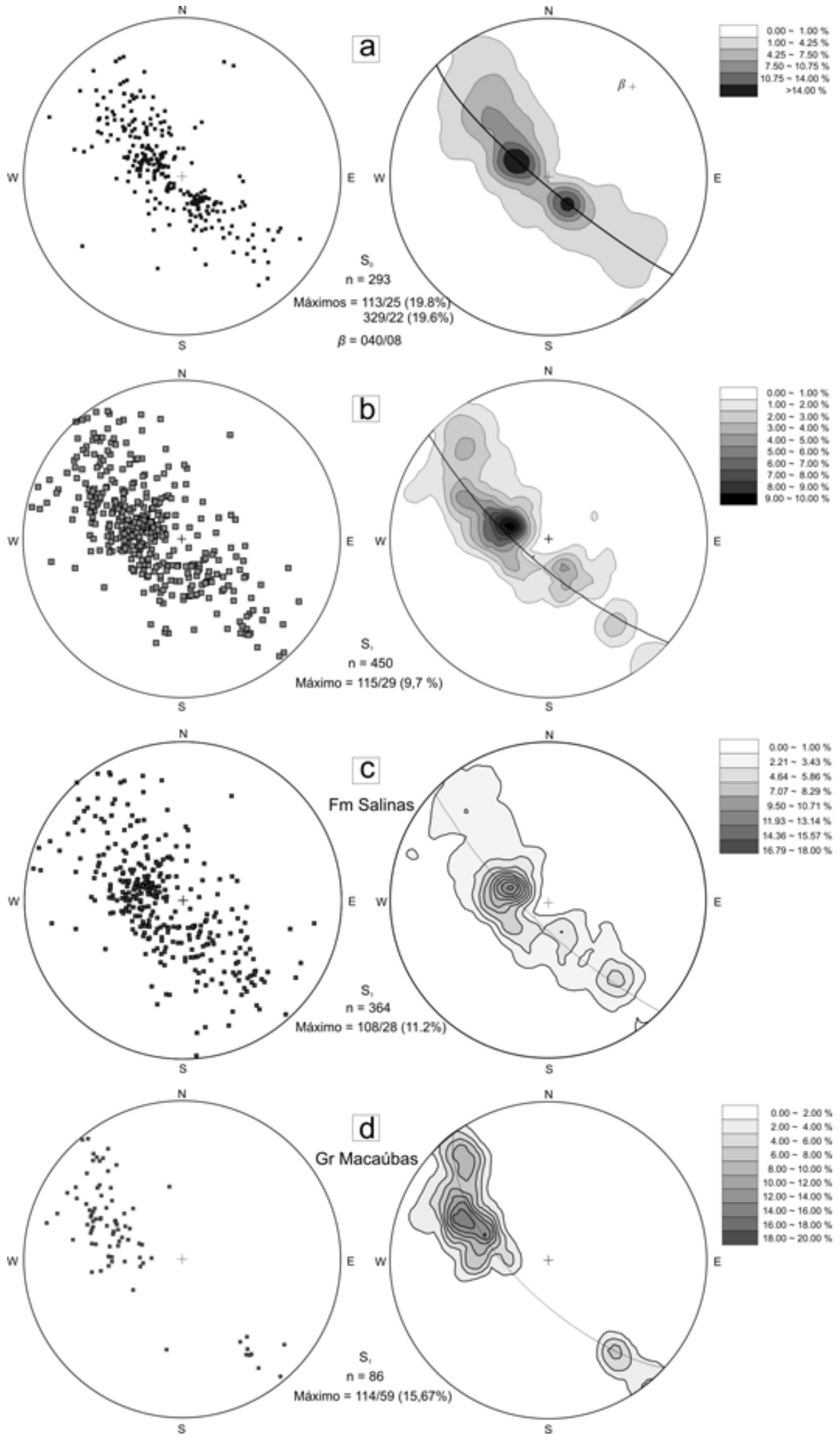

Figura 8 - Estereogramas do acamamento $S_{0}$ e da clivagem $S_{1}$ na área estudada. a) Estereogramas sinópticos do acamamento; b) Estereogramas sinópticos da clivagem $S_{1}$; c) Estereogramas de $S_{1}$ para o compartimento $W$ (zona de ocorrência do Grupo Macaúbas); d) Estereogramas de $S_{1}$ para o compartimento C (zona de ocorrência da Formação Salinas). 

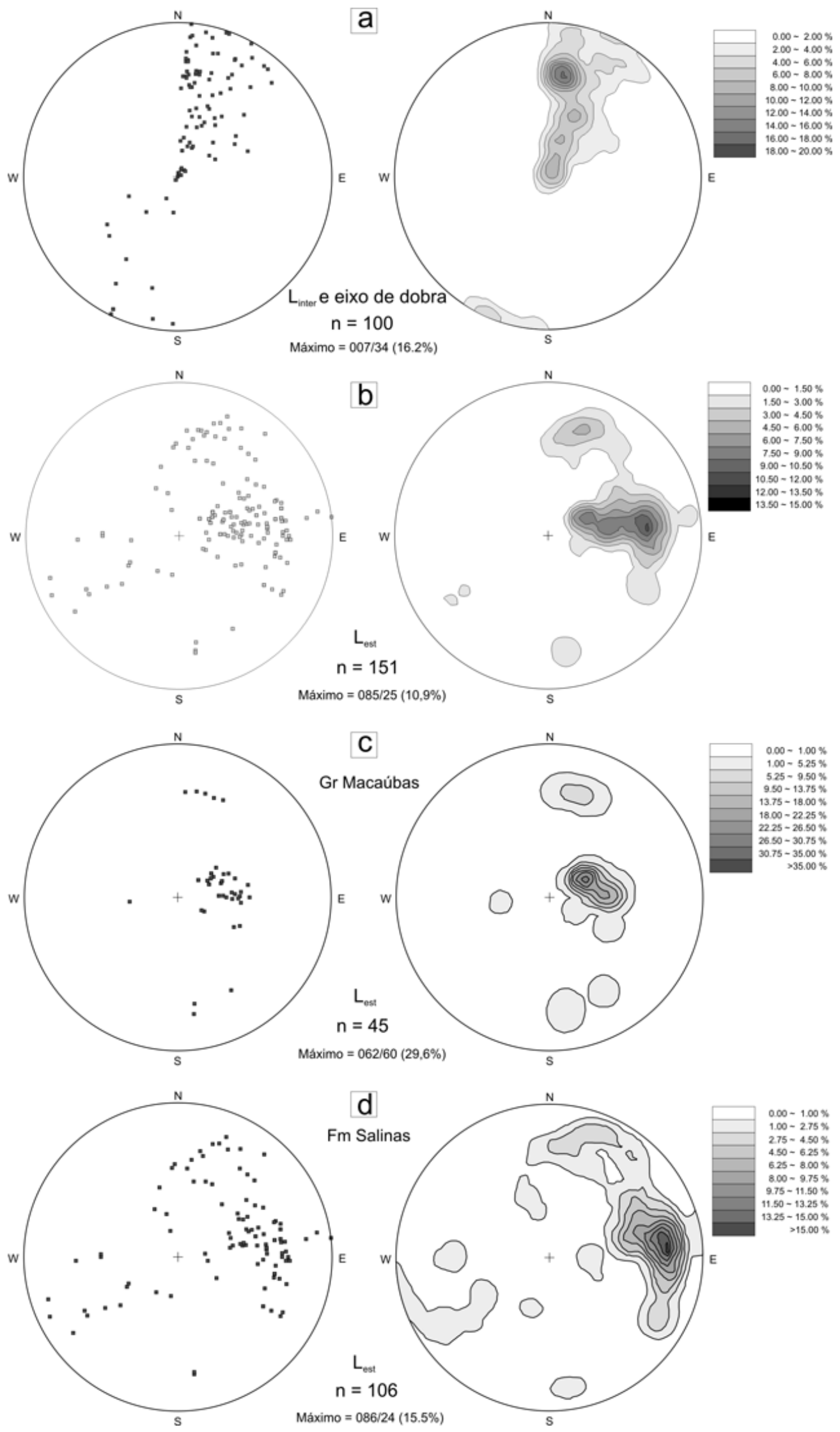

Figura 9 - Estereogramas das estruturas lineares da fase $D_{l}$. a) Estereograma sinóptico de eixos $\left(b_{l}\right)$ das dobras $F_{l}$ e da lineação de intersecção entre o acamamento e a clivagem $S_{1}\left(L_{i n}\right)$; b) Estereograma sinóptico da lineação de estiramento $\left(L_{\text {es }}\right)$; c) Estereograma da lineação de estiramento no compartimento W (zona de ocorrência do Grupo Macaúbas); d) Estereograma da lineação de estiramento no compartimento C (zona de ocorrência da Formação Salinas). 

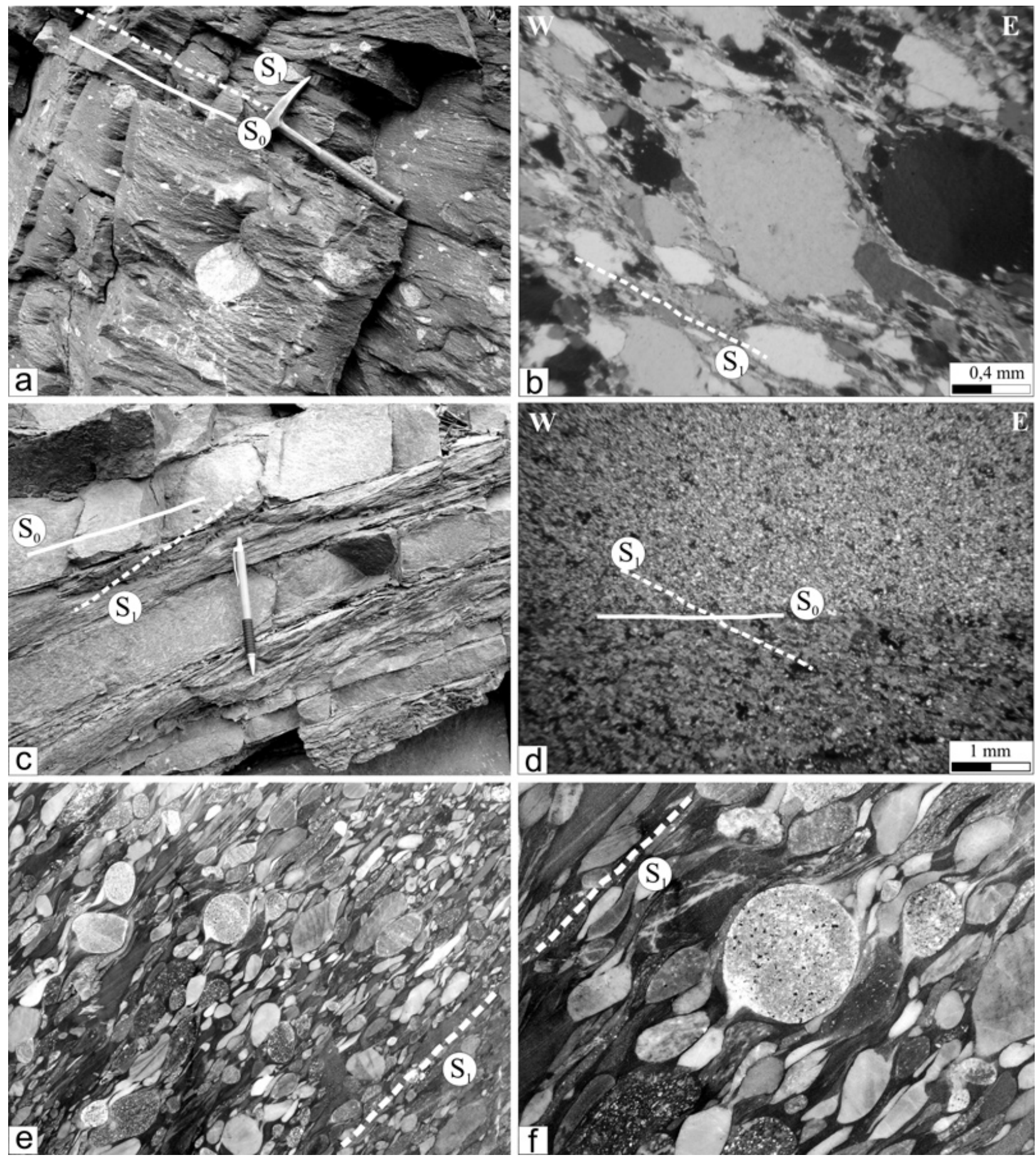

Figura 10 - Manifestações da clivagem $S_{1}$ nos litotipos da área estudada. a) $S_{0}$ e $S_{1}$ no metadiamictito Macaúbas; b) Fotomicrografia do metadiamictito Macaúbas onde $S_{1}$ se manifesta; c) e d) $S_{0}$ e $S_{1}$ em metarenito da Formação Salinas; d) e e)Manifestação de $S_{1}$ nos metaconglomerados da Formação Salinas (pedreira a $10 \mathrm{~km}$ a norte de Salinas).

ritmitos e metapelitos da Formação Salinas, onde as superfícies do acamamento e foliação são bem marcadas. Possui a atitude modal de 007/34, concordante com a orientação geral dos eixos das dobras $\mathrm{F}_{1}$ e fazendo ângulo de cerca de com $80^{\circ}$ com a lineação $\mathrm{L}_{\text {est }}$ (Fig. 9).

ZONAS DE CISALHAMENTO DÚCTEIS E FALHAS Zonas de cisalhamento dúcteis e dúctil-rúpteis apresentam-se com porte centimétrico a quilométrico e são de dois tipos: de empurrão e transcorrentes. As primeiras foram observadas principalmente em domínios de alto contraste de ductibilidade, normalmente em lâminas e camadas de metapelitos intercaladas em bancos espessos de meta-arenitos, no interior das grandes dobras da região (Fig. 7). Orientam-se preferencialmente na direção NNE e podem mergulhar tanto para ESSE, quando para WNW. As zonas transcorrentes, por outro lado, são em geral, verticais, dextrais, e de direção NE-SW. São freqüentes no 
setor noroeste da região estudada e têm como expressão regional os grandes lineamentos de direção NE-SW, evidentes nas imagens de sensores remotos.

Na maioria dos casos, ambos os tipos de zonas de cisalhamento são marcados por foliações anastomóticas e uma grande variedade de indicadores cinemáticos. Nas suas adjacências a foliação $S_{1}$, quando presente, rotaciona-se, a elas se amolda e evolui para foliações de natureza milonítica.

A maioria das falhas observadas apresenta rejeitos apenas centimétricos, responsáveis, portanto, por acomodar somente deformação localizada. Possuem direção preferencial NE-SW e o sentido de movimento observado é reverso-dextral. Uma delas, entretanto, se destaca: a Falha de Taiobeiras, que marca o contato entre o Grupo Macaúbas e a Formação Salinas, na porção noroeste da área estudada (Fig. 4). Com notável expressão em imagens, é, entretanto, de difícil caracterização em campo, em virtude da qualidade dos afloramentos. Em função de sua orientação geral e estruturas associadas, é interpretada como uma falha transcorrente dextral a reversa-dextral, possivelmente reativada como falha normal durante a fase de deformação $\mathrm{D}_{2}$ (vide adiante).

ASPECTOS CINEMÁTICOS E DINÂMICOS DA FASE $D_{1}$ Os indicadores cinemáticos associados aos elementos $\mathrm{D}_{1}$ presentes na Formação Salinas atestam um fluxo deformacional dirigido, preferencialmente para WNW e, subordinadamente, para ESE, respectivamente, nas porções oeste e leste da região investigada. A natureza e a disposição espacial do conjunto de estruturas $\mathrm{D}_{1}$ levam à conclusão de que, nesta fase, vigorou um regime compressional, modificado, nos setores noroeste e oeste da área estudada por uma componente de movimentação transcorrente dextral. Nesse regime, a tensão principal máxima $\left(\sigma_{1}\right)$ devia se posicionar próximo da horizontal e em torno da direção E-W, como indicado pela orientação preferencial da lineação de estiramento, dos eixos das dobras e das zonas de cisalhamento.

Estruturas da fase $\mathbf{D}_{2}$ As estruturas da fase $\mathrm{D}_{2}$ têm a sua ocorrência restrita a uma faixa de cerca de $15^{2} \mathrm{~km}$ de largura, de direção geral NNE-SSW e mergulho médio de $45^{\circ}$ para ESE na porção oeste da área estudada, ali definindo a zona de cisalhamento da Chapada Acauã, tal como caracterizada por Marshak et al. (2006) e descrita por Gradim et al. (2005) em área mais a sul (Fig. 2). Afetam as rochas do Grupo Macaúbas até a sua zona de contato com as rochas da Formação Salinas.

Um papel importante exercido pela Zona de Cisalhamento Normal da Chapada Acauã é promover o abatimento, em direção a leste, de todo o pacote da Formação Salinas, fazendo com que haja um retorno às condições metamórficas da fácies xisto verde na zona mais interna do orógeno. Por esta razão verifica-se a aparente incompatibilidade entre a polaridade estrutural do orógeno e a distribuição das fácies metamórficas nas seções oeste/leste através da área estudada.

DOBRAS $F_{2}$ As dobras $\mathrm{F}_{2}$, juntamente com a clivagem
$\mathrm{S}_{2}$ são os elementos mais conspícuos da Zona de Cisalhamento Chapada Acauã e, conseqüentemente, da etapa $\mathrm{D}_{2}$. São assimétricas, abertas a apertadas, de escala milimétrica a métrica. Exibem vergência geral para ESE e tem a sua superfície envoltória mergulhando no mesmo sentido. Suas charneiras mostram baixo caimento tanto para NNE, como para SSW (Figs. 11 e 12).

\section{CLIVAGEM $S_{2}$ E LINEAÇÃO DE CRENULAÇÃO}

$L_{2}$ Às dobras $\mathrm{F}_{2}$ associa-se uma clivagem de crenulaçã̃o $\left(\mathrm{S}_{2}\right)$ (Fig. 11), cujas cristas definem uma lineação de crenulação $\left(\mathrm{L}_{2}\right)$, muito evidente nos filitos da Formação Chapada Acauã do Grupo Macaúbas.

Quando observada na escala microscópica, a clivagem $\mathrm{S}_{2}$ apresenta-se em bandas discretas de espessuras milimétricas (de $0,5 \mathrm{a} 3 \mathrm{~mm}$ ) e espaçamento variável entre $1 \mathrm{~mm}$ e $5 \mathrm{~cm}$. São formadas pela rotação passiva de micas e dissolução por pressão dos grãos e agregados de quartzo. Os diagramas estereográficos para $\mathrm{S}_{2}$ e $\mathrm{L}_{2}$ mostram as orientações preferenciais de 288/56 e 014/05, respectivamente (Fig. 12).

ZONAS DE CISALHAMENTO ZC, Zonas de cisalhamento dúctil-rúpteis normais de espessuras variáveis entre 20 e $40 \mathrm{~cm}$, com rejeitos métricos e espaçamento na casa das dezenas de metros, também fazem parte do conjunto de estruturas $\mathrm{D}_{2}$. Possuem traços verticais lístricos, mergulhos médios de $60^{\circ}$ para WNW e promovem a rotação e obliteração local de todas as estruturas pré-existentes por elas afetadas (Fig. 11). Em função da sua orientação e movimento associado, podem ser consideradas antitéticas em relação à Zona de Cisalhamento Chapada Acauã que as hospeda.

\section{ASPECTOS CINEMÁTICOS E DINÂMICOS DA FASE} $D_{2}$ Os elementos estruturais da fase $\mathrm{D}_{2}$ caracterizam transporte tectônico geral dirigido para ESE, ao longo de superfícies que mergulham no mesmo sentido, ou seja, uma movimentação de caráter normal. Subordinadamente, as zonas de cisalhamento $\mathrm{ZC}_{2}$ caracterizam fluxo normal no sentido oposto. Como postulado por Marshak et al. (2006), no seu conjunto, as estruturas $\mathrm{D}_{2}$ implicam em uma tensão principal máxima $\left(\sigma_{1}\right)$ posicionada na vertical, desta forma caracterizando um regime tectônico distensional.

Estruturas da fase $\mathbf{D}_{\mathbf{G}}$ Os elementos das fases $\mathrm{D}_{\mathrm{D}}$ e $\mathrm{D}_{1}$ presentes na Formação Salinas encontram-se, localmente, afetados ou mesmo obliterados por estruturas claramente relacionadas a intrusões graníticas. Essa modificação ocorre, essencialmente, na porção leste e sudeste da área, onde as rochas Salinas acham-se intrudidas por corpos graníticos e pegmatíticos (Fig. 13). Além de rotações desordenadas das estruturas preexistentes, as intrusões deram origem a dobras de cobertura abertas a suaves. Exemplos destas estruturas e sua associação com corpos intrusivos podem ser observados nos cortes da rodovia que liga as cidades de Coronel Murta e Salinas. Como mencionado, a relação cronológica entre as fases $\mathrm{D}_{\mathrm{G}}$ e $\mathrm{D}_{2}$ é indefinida na região, em função da ausência de relações 

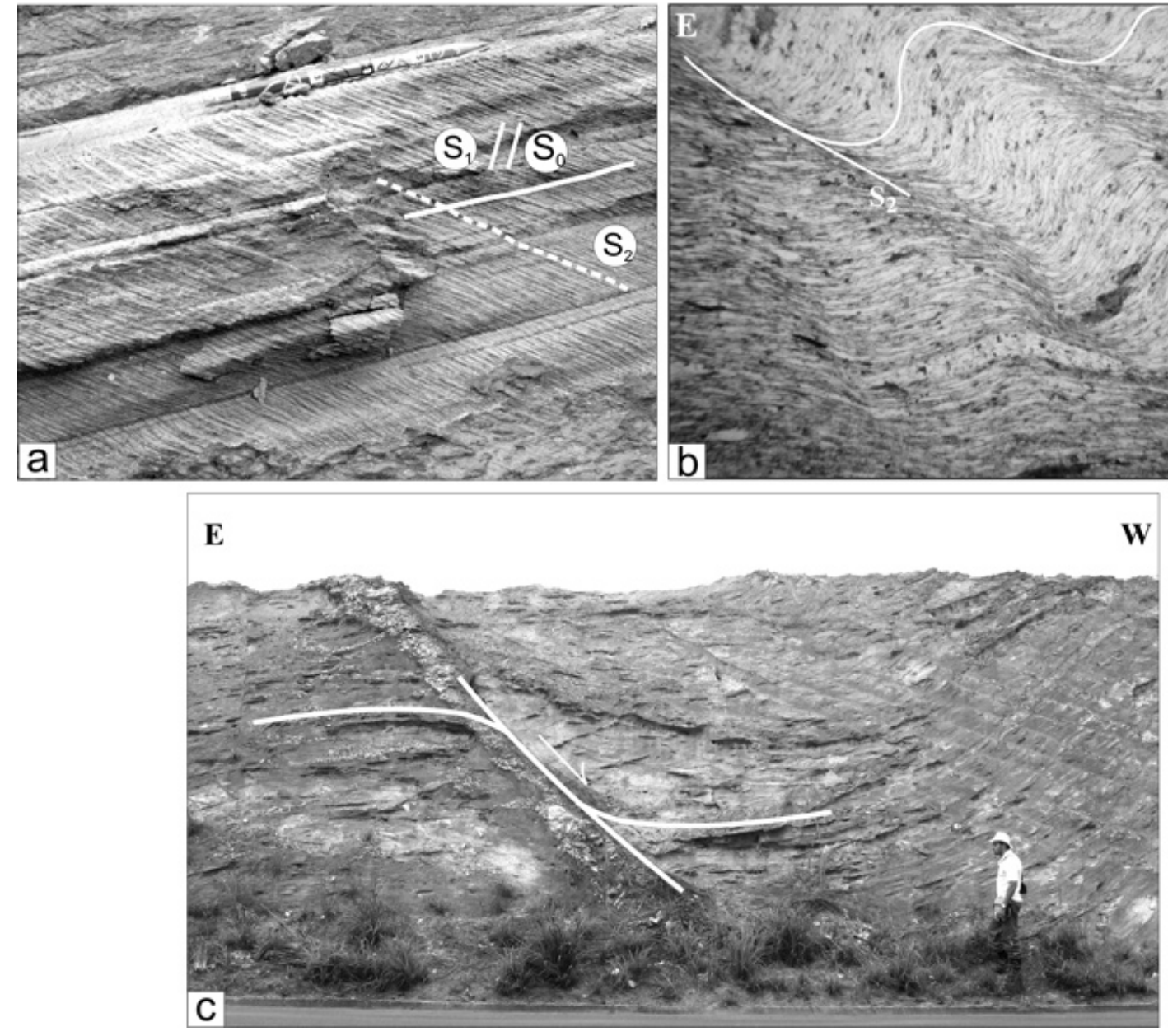

Figura 11 - Estruturas da fase $D_{2}:$ a) Expressão de $S_{1}$ paralelo a $S_{0^{\prime}}$ truncado pela clivagem de crenulação $S_{2}$; b) Fotomicrografia de metapelito do Grupo Macaúbas exibindo a clivagem $S_{2}$ superimposta à foliação $S_{I}$; c)Zona de cisalhamento dúctil-rúptil de movimentação normal que afeta metapelitos da Formação Chapada Acauã (BR 251-próxima à localidade de Fruta de Leite).

de corte e superposição de seus elementos.

MODELO EVOLUTIVO E SIGNIFICADO TECTÔNICO DA FORMAÇÃO SALINAS Em função do que foi descrito nas seções anteriores e de dados obtidos na literatura, têm-se como principais características da Formação Salinas as seguintes:

- corresponde a um pacote de rochas turbidíticas acumulado em uma bacia profunda sujeita a processos sedimentares de alta energia, desencadeados, provavelmente por atividade sísmica;

- o seu substrato é constituído, a oeste, por rochas da margem passiva distal da Bacia Macaúbas; a leste, é intrudida por granitos de idade cambriana $(\sim 500 \mathrm{Ma})$;

- a sua deposição deu-se no intervalo compreendido entre 588+/- $24 \mathrm{Ma}$ (idade máxima obtida através de zircões detríticos, Pedrosa-Soares et al. 2008) e ca. $500 \mathrm{Ma}$ (idade dos corpos graníticos que a intrudem).

$\mathrm{O}$ fato da Formação Salinas registrar a fase de deformação principal documentada na porção norte do Orógeno Araçuaí, a fase $\mathrm{D}_{1}$ (sin-metamórfica e sin-colisional) implica em que sua deposição tenha se dado, mais precisamente, no intervalo compreendido entre

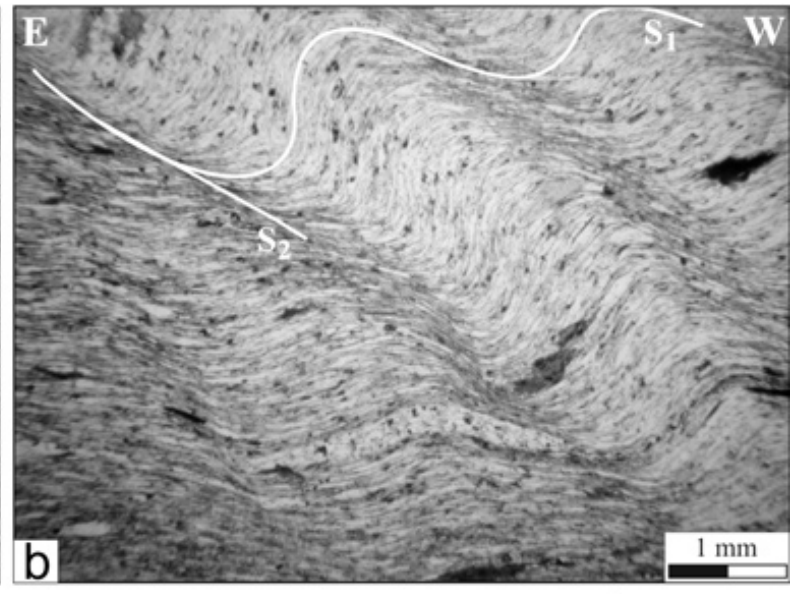

W 

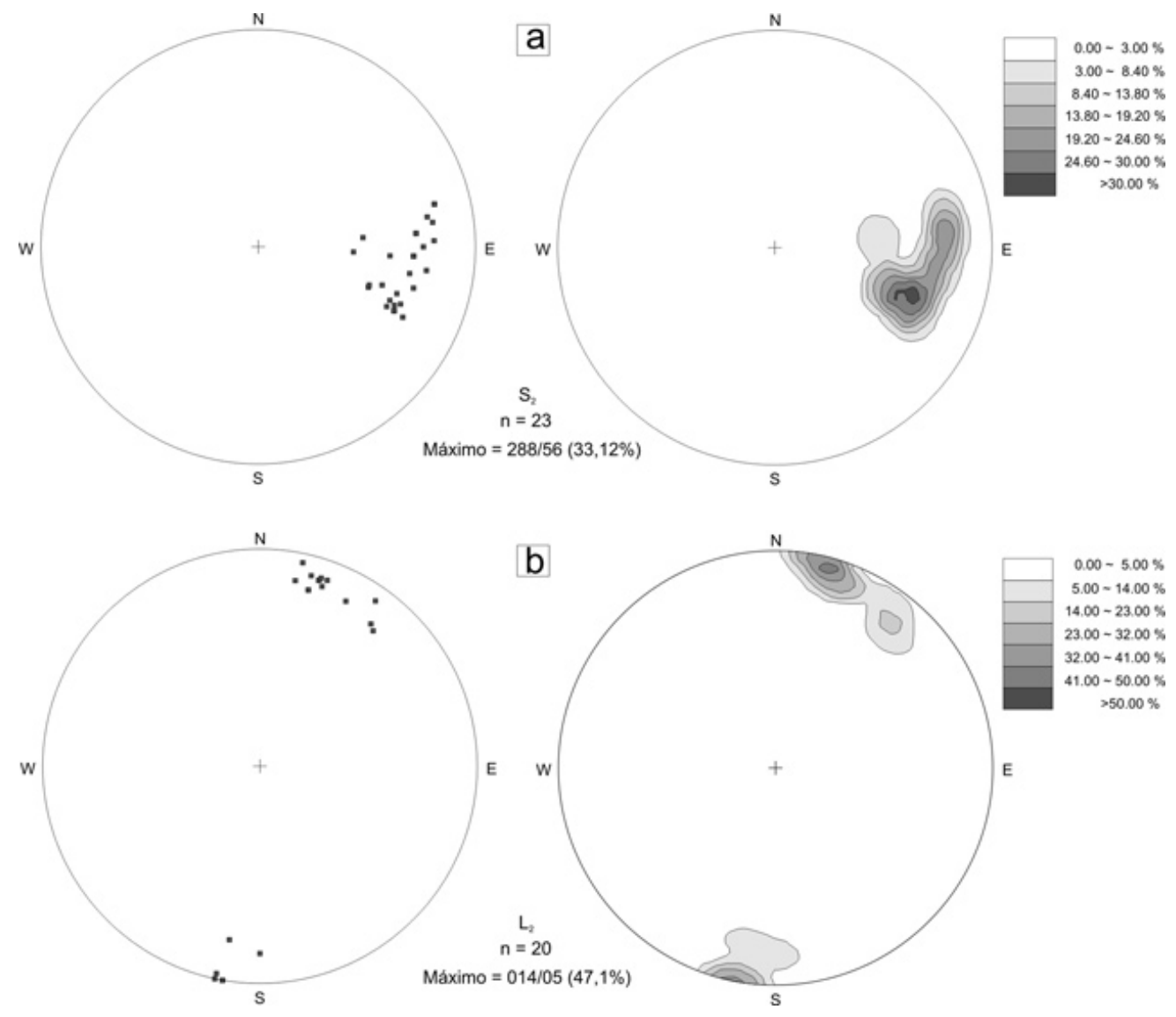

Figura 12 - Estereogramas das estruturas $D$ a) Estereograma sinóptico da a clivagem de crenulação $S_{2}$; b) Estereograma sinóptico da lineação de crenulação $L_{2}$.

mos em geologia. Seu emprego indiscriminado terminou por erodir o seu sentido original. No Orógeno Alpino, onde foi cunhado, o termo designa um espesso pacote turbidítico de grande distribuição geográfica, acumulado em uma bacia marinha profunda ou antefossa desenvolvida entre uma margem passiva (a margem do continente europeu) e um arco magmático em interação colisional inicial (Microplaca Adria - Alpes Ocidentais) (Pfiffner 1966, Windley 1995). Nestas condições, o seu substrato é constituído, de um lado, pela porção distal da margem passiva e, do outro, pelo prisma acrescionário do complexo de subducção que dela se aproxima. A alimentação da seqüência turbidítica provém de duas fontes básicas: da margem passiva em início de soerguimento e do arco magmático e frente de empurrões. O pacote tem grande contribuição de material carbonático, tanto na forma de detritos provenientes da margem passiva, como na forma de leitos de margas e lamitos pelágicos intercalados em pelitos distais. A seqüência como um todo é progradante, mostra crescimento da granulometria para topo e é pobre em macrofósseis. O início da deposição deu-se no intervalo superior do Cretáceo superior (aprox. $90 \mathrm{Ma}$ ) e perdurou até a metade do Eoceno (40 Ma). Ou seja, corresponde exatamente aos 50 Ma do estágio orogênico alpino (Geyer 1977, Seilacher 1967).

Associações sedimentares de mesma natureza foram reconhecidas em vários orógenos, podendo-se citar os Apalaches (Willians 1984), os Cárpatos (Royden \& Karner 1984), os Urais (Brown et al 1995), o Variscano (Matte 1991).

No caso do Orógeno Araçuaí, condições muito semelhantes às descritas nos trabalhos anteriormente mencionados devem ter vigorado mais a sul da área de ocorrência atual da Formação Salinas, onde se tem um arco magmático suturado a sedimentos de margem passiva, representados pelas formações superiores do Grupo Macaúbas. Na zona atual de ocorrência da Formação Salinas, a bacia Macaúbas, precursora do orógeno, seria integralmente de natureza ensiálica (Pedrosa-Soares et al. 2001, Alkmim et al. 2006). Corresponderia a um rifte amplo, com duas margens bem desenvolvidas, mas sem a participação de litosfera oceânica. Durante o seu fechamento, não existiria, portanto, uma zona de subducção, nem tão pouco, o arco magmático a ela associado. Este processo, que poderia ser descrito como de inversão de uma bacia rifte muito desenvolvida, causaria, entretanto, a formação de uma cunha de empurrões na margem da bacia contigua à placa superior da zona de subdução e a migração do front orogênico de leste para oeste. À frente da cunha, formar-se-ia uma antefossa, na qual se acumulariam os turbiditos Salinas (Fig. 14).

Com a continuidade da convergência das margens e fechamento da bacia, os sedimentos Salinas seriam capturados pela frente orogênica, deformados 

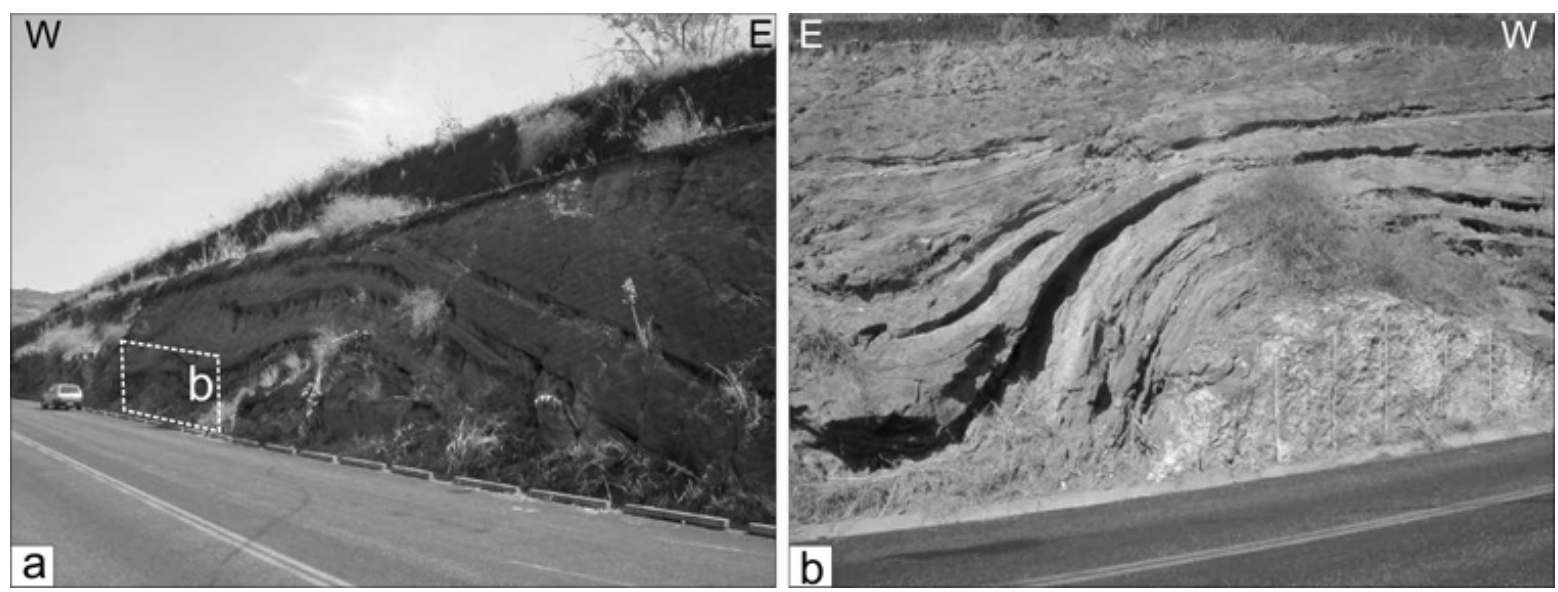

Figura 13 - Estruturas da fase $D_{G}$ a) amplo arqueamento dos estratos da Formação Salinas sobre um corpo pegmatítico associado aos granitos da Suite G4; b) detalhe da figura anterior mostrando a zona de contato entre o corpo pegmatítico e a Formação Salinas. (BR 342 - 50 km a SSE de Salinas).

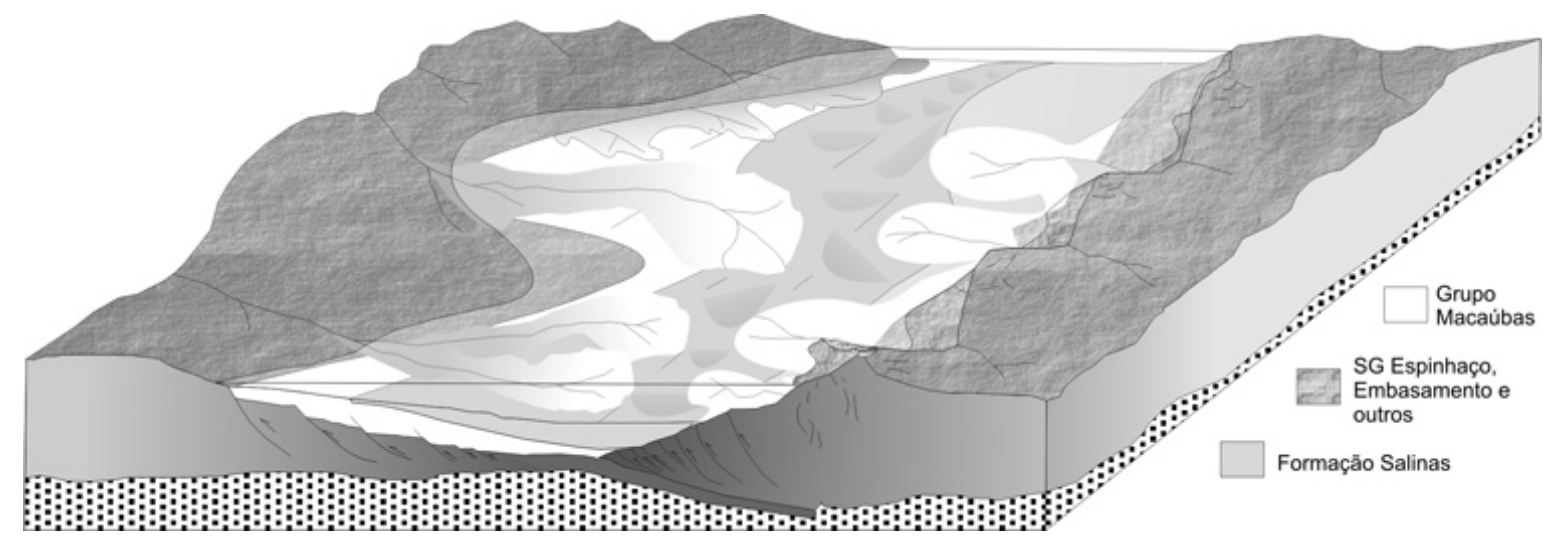

Figura 14 - Bloco-digrama ilustrando o contexto deposicional da Formação Salinas (vide texto para explanação).

e metamorfisados. A cerca de 40 Ma após o seu soerguimento o Orógeno Araçuaí entra em colapso gravitacional (Alkmim et al. 2006, 2007). Instala-se o regime distensional e forma-se, assim, a Zona de Cisalhamento Chapada Acauã, a qual promove o abatimento, em direção a leste, de todo o pacote Salinas. Este processo dá origem ao zoneamento metamórfico atípico da zona de ocorrência da Formação Salinas anteriormente. Ou seja, deslocamento do pacote Salinas ao longo da zona de cisalhamento normal Chapada Acauã promove um retorno às condições metamórficas da fácies xisto verde junto ao núcleo do orógeno.

CONCLUSÕES Os resultados obtidos na investigação estrutural realizada nas rochas da Formação Salinas e unidades que com ela fazem contato na região da cidade homônima, norte de Minas Gerais, permitem concluir que :

- A associação de litofácies observada na Formação Salinas indica uma deposição em sistema de leques turbidíticos, associados aos ambientes de plataforma, talude e bacia profunda, tal como sugerido por
Lima et al. (2002).

- As rochas da Formação Salinas exibem estruturas deformacionais relativas a três fases deformacionais. A primeira fase, sindeposicional e de natureza adiastrófica, resulta, provavelmente, de alta sismicidade no sítio deposicional. A segunda, acompanhada de metamorfismo regional, foi a responsável pela nucleação, sob um campo compressivo E-W, das estruturas dominantes regionalmente e reflete a fase colisional principal do Orógeno Araçuaí, que teve lugar entre 580 e $560 \mathrm{Ma}$. A terceira, de caráter local e acompanhada de um evento de metamorfismo de contato, corresponde à deformação causada nas encaixantes pela colocação de corpos graníticos, por volta de 500 Ma.

- Um evento metamórfico regional nas condições das fácies xisto verde a anfibolito afeta os metassedimentos da Formação Salinas e do Grupo Macaúbas, respectivamente. A Formação Salinas guarda ainda feições que registram um evento de metamorfismo de contato associado às intrusões graníticas presentes na porção leste da área. 
- As características da Formação Salinas permitem enquadrá-la como uma seqüência sin-orogênica (flysch), acumulada em uma bacia marinha profunda ou antefossa, que se desenvolveu entre uma margem passiva e uma frente de empurrões, de modo a ser alimentada por ambos.

Agradecimentos O presente trabalho foi desenvolvido no âmbito de um projeto de mestrado no Departamento de Geologia da Escola de Minas da Universidade Federal de Ouro Preto, instituição à qual o primeiro autor manifesta os seus agradecimentos. Agradece também ao CNPq pela bolsa de mestrado concedida. Os demais autores são pesquisadores do $\mathrm{CNPq}$ e para o projeto em questão receberam auxílio através do processo $\mathrm{n}^{\circ}$ 477618/2003-0. Com críticas e sugestões dois revisores anônimos muito contribuíram para aprimoramento do presente trabalho.

\section{Referências}

Alkmim F.F., Marshak S., Pedrosa-Soares A.C., Peres G.G., Cruz, S.C.P., Whittington A. 2006. Kinematic Evolution of the Aracuaí-West Congo orogen in Brazil and Africa: Nutcracker tectonics during the Neoproterozoic assembly of Gondwana. Precambrian Research., 149:43-64.

Alkmim F.F., Pedrosa-Soares A.C., Noce, C.M., Cruz, S.C.P. 2007. Sobre a evolução tectônica do Orógeno AraçuaíCongo Ocidental. Geonomos, 15(1):25-43.

Brown D., Puchkov V., Alvarez-Marron J., Perez-Estaun A.1995. The structural architecture of the footwall to the Main Uralian fault, southern Urals. Earth Sciences Reviews, 40:125-147.

Correia-Neves J.M., Monteiro R.L.B.P., Pedrosa-Soares A.C. 1982. Granitóides da região de Coronel Murta, Minas Gerais. In: Cong. Lat. Am. Geol., 5, Buenos Aires, Atas, vol.2, p. 133-146.

Correia-Neves J. M., Pedrosa-Soares A.C., Monteiro R.L.B.P., Scliar C. 1983. Contribuição à geologia e petrografia da região pegmatítica de Virgem da Lapa - Coronel Murta, MG. In: SBG Núcleo MG, Simp. Geol. Minas Gerais, 2, Belo Horizonte, Anais, p. 100-114.

Costa A.G. 1989. Evolução Petrológica para uma seqüência de rochas metamórficas regionais do tipo baixas pressão na região de Itinga, NE de Minas Gerais. Revista Brasileira de Geociências, 19(4):440-448.

Chapple W.M. 1978. Mechanics of thin-skinned fold-andthrust belts. Geological Society of America Bulletin, 89:1189-1198.

Crocco-Rodrigues F.A., Guimarães M.L.V., Abreu F.R., Oliveira O.A.B., Greco F.M. 1993. Evolução Tectônica do Bloco Itacambira-Monte Azul entre Barrocão e Porteirinha - Minas Gerais. In: SBG-MG, Simp. Nac. Est. Tec., 4, Belo Horizonte, Atas, v. 12, p. 212-216.

Davis G.A., Suppe J., Dahlen F.A. 1983. Mechanics of fold and thrust belts and accretionary wedges. Journal of Geophysical Research, 88:1153-1172

Dussin I.A. \& Dussin T.M. 1995. Supergrupo Espinhaço: Modelo de evolução geodinâmica. Geonomos, 3(1):1926.

Elliot D. 1976. The motion of thrust sheets. Journal of Geophysical Research, 81:949-963

Fontes C.Q., Ferrari P.G., Pereira A.A.C., Netto C., Pereira F.S., Lima L.O.J., Costa M.R. A., Baltazar O.F., Silva S.L., Vieira V.S., Ramalho R. 1978. Projeto Jequitinhonha. Escala 1: 250.000. Belo Horizonte, DNPM/CPRM, Relatório Final, 368p.

Geyer O.F. 1977. Grundzüge der Stratigraphie um Fazies- kunde. Vol. 2. Stuttgart, E.Schwizerbart'sche Verlagsbuchandlung, 341p.

Gradim R.J., Alkmim, F.F., Pedrosa-Soares, A.C., Babinski, M., Noce, C.M. 2005. Xistos verdes do alto Araçuaí, Minas Gerais: Vulcanismo básico do rifte neoproterozóico Macaúbas. Rev.Bras. de Geociências, 35(4Suplemento):59-69.

Grossi-Sad J.H., Lobato L.M., Pedrosa-Soares A.C., SoaresFilho B.S. (coords. e eds). 1997. Projeto Espinhaço em CD-ROM (textos, mapas e anexos). Belo Horizonte, COMIG, 2693p.

Karfunkel J., Schmidt J.C., Karfunkel B.S. 1981. Contribuição à Estratigrafia e Tectônica da Faixa de Dobramentos Araçuaí. In: SBG/Ba, Simpósio sobre o Cráton do São Francisco e suas Faixas Marginais 1, Salvador, 1979. Anais, p. 45-49.

Karfunkel J., Pedrosa-Soares A.C., Dossin I.A. 1985. O Grupo Macaúbas em Minas Gerais, revisão dos conhecimentos. In: SBG, Simp. Geol. MG, 3, Atas, p. 45-59.

Lima S.A.A., Martins-Neto M., Pedrosa-Soares A.C., Cordani U.G., Nutman A. 2002. A Formação Salinas na áreatipo, NE de Minas Gerais: uma proposta de revisão da estratigrafia da Faixa Araçuaí com base em evidências sedimentares, metamórficas, e idades U-Pb SHRIMP. Revista Brasileira de Geociências, 32: 491-500.

Lowe D.R. 1975. Water escape structures in coarse-grained sediments. Sedimentology, 22:485-501

Marshak S., Alkmim F.F., Whittington A., Pedrosa-Soares A.C. 2006 Extensional collapse in the Neoproterozoic AraçuaÌ orogen, eastern Brazil: A setting for reactivation of asymmetric crenulation cleavage. Journal of Structural Geology, 28:129-147.

Matte P. 1991. Acrescionary history and crustal evolution of the Variscan belt in Europe.Tectonophysics, 196:309-337

Monteiro R.L.B.P. 1986. As Mineralizações de Tungstênio no Médio Vale do Jequitinhonha, NE de Minas Gerais, Brasil. Dissertação de Mestrado, Brasília, UnB/DGC, $171 \mathrm{p}$.

Noce C.M., Pedrosa-Soares A.C., Grossi-Sad J.H., Baars F.J., Guimarães M.L.V., Mourão M.A.A., Oliveira M.J.R., Roque N.C. 1997. Nova divisão estratigráfica regional do Grupo Macaúbas na Faixa Araçuaí: o registro de uma bacia neoproterozóica. In: Simp. Geol. MG, 9, Atas, p. 29-31.

Pedrosa-Soares A.C. 1984. Metamorfismo, granitogênese e mineralizações associadas na região de Coronel Murta, NE de Minas Gerais. Dissertação de Mestrado, Brasília, 
UnB/DGC, 236p.

Pedrosa-Soares A.C. 1995. Potencial aurifero do Vale do Araçuai, MG: História da exploração, geologia e controle tectono-metamórfico. Tese de Doutoramento, Instituto de Geociências, Universidade de Brasília, 177p.

Pedrosa-Soares A.C. \& Oliveira M.J.R.1997. Geologia da Folha Salinas. In: Grossi-Sad J.H., Lobato L.M., Pedrosa-Soares A.C., Soares-Filho B.S. (coords. e eds.). Projeto Espinhaço em Cd-Rom (textos, mapas e anexos). Belo Horizonte, COMIG.

Pedrosa-Soares A.C. \& Saadi A.1989. O Segmento meridional da Falha de Taiobeiras, MG. In: SBG-Núcleo MG, Simp. Geol, 5, Belo Horizonte, Atas, Bol. no 10, p.161165.

Pedrosa-Soares A.C., Monteiro R. L. B. P., Correia-Neves J. M., Leonardos O. H., Fuzikawa K. 1987. Metasomatic evolution of granites, northeast Minas Gerais, Brazil. Revista Brasileira de Geociências, 17 (4):512-518.

Pedrosa-Soares A.C., Monteiro R.L.B.P., Noce C.M, Freitas e Silva F.H., Oliveira M.J.R., Schettino A., 1990. Caracterização de uma seqüência vulcano-sedimentar distal na Faixa Araçuaí, MG: bacia oceânica restrita? In: SBG Núcleo Nordeste, Cong. Bras. Geol., 36, Natal, Boletim de Resumos, p. 308-308.

Pedrosa-Soares A.C., Noce C.M., Vidal P., Monteiro R.L.B.P., Leonardos O.H. 1992. Toward a new tectonic model for the Late Proterozoic Araçuaí (SE Brazil)-West Congolian (SW Africa) Belt. Journal of South American Earth Sciences, 6(1/2):33-47.

Pedrosa-Soares A.C. \& Wiedemann-Leonardos C.M. 2000. Evolution of the Araçuaí Belt and its connection to the Ribeira Belt, eastern Brazil. In: Cordani U.G., Milani E.J., Thomaz Filho A., Campos D.A. (eds.) Tectonic Evolution of South America. Rio de Janeiro/IGC 2000, p. 265-285.

Pedrosa-Soares A.C., Noce C.M., Wiedemann C.M., Pinto C.P. 2001. The Araçuaí-WestCongo Orogen in Brazil: An overview of a confined orogen formed during Gondwanaland assembly. Precambrian Research, 110:307-323.

Pedrosa-Soares A.C., Alkmim F.F., Tack L., Noce C.M., Babinski M., Silva L.C.; Martins-Neto, M. 2008. Similarities and differences between the Brazilian and African counterparts of the Neoproterozoic Araçuaí-West Congo Orogen. In: Pankhurst J.R., Trouw R.A.J., Brito Neves B.B., De Wit M.J.(eds.) West Gondwana: Pre-Cenozoic Correlations across the South Atlantic Region. Geological Society of London, Spec.Publ., 294:153-172.

Pfiffner O.A. 1986. Evolution of the north Alpine foreland basin in the Central Alps. In: Allen and Homewood (eds.) Foreland basins. Int. Assoc. Sediment.,Oxford, Blackwell, Spec. Publ., 8:219-228.

Royden L.H \& Karner G.D. 1984. Flexure of the lithosphere beneath Apennine and Carpathian foredeep basins: evidence for an insufficient topographic load. American Association of Petroleum Geolologists Bulletin, 68:704712.

Sá J.H.S. 1977. Pegmatitos litiniferos da região de ItingaAraçuaí, Minas Gerais. Tese de Doutoramento. IGSUSP, São Paulo, 104p.

Saadi A.J. \& Pedrosa-Soares A.C. 1990. Um graben cenozói- co no Médio Jequitinhonha, Minas Gerais. In: SBG-MG, Workshop sobre neotectônica e sedimentação cenozóica continental no sudoeste brasileiro, 1, Belo Horizonte. Atas, Belo Horizonte, Bol. 11, p.101-124.

Schobbenhaus C, Silva A.S., Mignon R.A., Neves S.B., Leão E., Pimentel E.C., Derze G.E. 1978. Carta Geológica do Brasil ao Milionésimo. Folha SE-23 (Belo Horizonte), Brasília, DNPM/DGM.

Schobbenhaus C, Campos D.A., Derze G.R., Asmus H.E. 1981. Mapa Geológico do Brasil, 1: 2500000 (cartas e mapas), Brasília, DNPM.

Siga Jr. O. 1986. A evolução geotectônica da Porção Nordeste de Minas Gerais com base em interpretações geocronológica. Dissertação de Mestrado, São Paulo, Instituto de Geociências, USP, 140p.

Seilacher A. 1967. Tektonischer, sedimentologischer and biologischer Flysh ? Geologischer Rundschau, 56: 189200.

Tack L., Wingate M. T. D., Liégeois J. P., Fernandez-Alonso M., Deblond A. 2001. Early Neoproterozoic magmatism (1000-910 Ma) of the Zadinian and Mayumbian groups (Bas-Congo): onset of Rodinia at the western edge of the Congo craton. Precambrian Research, 110:277-306.

Trompette R. 1994. Geology of Western Gondwana (2000500 Ma): Pan-African-Brasiliano aggregation of South America and Africa. Amsterdam, Balkema, 350p.

Uhlein A. 1991. Transição cráton-faixa dobrada: exemplo do Cráton do São Francisco e da Faixa Araçuaí (Ciclo Brasiliano) no estado de Minas Gerais. Aspectos estratigráficos e estruturais. Tese de doutoramento, Instituto de Geociências, Universidade de São Paulo, 295 p.

Uhlein A., Dossin I.A., Chaves M.L.S.C. 1986. Contribuição à geologia estrutural e tectônica das rochas arqueanas e proterozóicas da Serra do Espinhaço Meridional-MG. In: SBG, Congr. Bras. Geol., 34, Anais, vol 3, p.11911203.

Uhlein A., Trompette R.R., Egydio-Silva M. 1990. A Faixa de Dobramentos Araçuaí no Estado de Minas Gerais, uma cadeia monocíclica de idade Brasiliana. In: SBG, Cong. Bras. Geol., 36, Natal, 1990, Anais, vol. 6, p. 2576-2588.

Uhlein A., Trompette R.R., Egydio-Silva M. 1998. Proterozoic rifting and closure, SE border of the São Francisco Craton, Brazil. Journal of South American Earth Sciences., 11(2):191-203.

Uhlein A., Trompette R. R., Alvarenga C. J. S. 1999. Neoproterozoic glacial and gravitational sedimentation on a continental rifted margin: The Jequitaí-Macaúbas sequence (Minas Gerais, Brazil). Journal of South American Earth Sciences, 12:435-451.

Windley B. F.1995. The Evolving Continents. England, John Wiley \& Sons Ltd, $3^{\text {rd }}$ ed, 526p.

Williams H. 1984. Miogeoclines and suspect terranes of the Calcedonian-Appalachian orogen: tectonic patterns in the North Atlantic region. Canadian Journal of Earth Sciences, 21:887-901.

Manuscrito ID 9729

Submetido em 08 de novembro de 2007 Aceito em 14 de fevereiro de 2009 